Review Articles

\title{
A Survey of Graph Based Complex Brain Network Analysis Using Functional and Diffusional MRI
}

\author{
${ }^{1}$ Md Rafiqul Islam, ${ }^{1}$ Xiaoxia Yin, ${ }^{2}$ Anwaar Ulhaq, \\ ${ }^{1}$ Yanchun Zhang, ${ }^{1}$ Hua Wang, ${ }^{3}$ Noreen Anjum and ${ }^{4}$ Tomas Kron \\ ${ }^{I}$ Centre for Applied Informatics (CAI), Victoria University, Melbourne, Australia \\ ${ }^{2}$ College of Engineering and Science, Victoria University, Melbourne, Australia \\ ${ }^{3}$ Preston University, Islamabad, Pakistan \\ ${ }^{4}$ Peter Maccallum Cancer Centre, Melbourne, Australia
}

Article history

Received: 06-11-2017

Revised: 22-12-2017

Accepted: 30-12-2017

Corresponding Author: Md Rafiqul Islam Centre for Applied Informatics (CAI), Victoria University, Melbourne, Australia Tel: +610470689925 Email: rafiqulislam.cse24@gmail.com

\begin{abstract}
The brain network is the function of a structurally and functionally organized complex system. Its structure and activity analysis is one of the most significant challenges. The graph based techniques of brain complex networks have been successfully used in various types of image and medical data analysis. In this survey paper, we focus on a comprehensive study of the analytical methods for complex brain network based on graph theory. This review paper is intended to provide automated brain disease diagnosis based on functional and diffusional MRI modalities. Furthermore, we discuss subjective and objective quality evaluations of complex brain networks, important tools for automated brain disease diagnosis, challenging issues and future research directions in this increasingly evolving research field.
\end{abstract}

Keywords: Functional MRI, Diffusion MRI, Graph Theory, Complex Network, Modality

\section{Introduction}

Our brain is a function of complex networks because its function is connected within different neural networks and brain regions. Almost everything we think, say and do is controlled by our brain, so when our brain is damaged, it is possibility to affect every aspect of our life (Bullmore and Sporns, 2012).

In the field of mathematics, graph theory is a major area to model relations between objects and to represent a connected network structure. Researchers are using graph theory to quantify aspects such as similarity, hierarchy and network efficiency of complex network structure in many other fields. Recently neuroscience researchers are proposed to use graph theory analysis to identify topological properties of complex brain network structure (Thirion et al., 2006; Bullmore and Sporns, 2009). A few years back, Grady and Polimeni (2010) published a book related to discrete calculus on graphs and described discrete calculus, matrix algebra briefly. In recent years, various researchers suggested that the combination of discrete calculus, matrix algebra on graph provides the extremely powerful computational toolbox for the analysis of human brain functions and structure. However, the ability to perform these computations on graphs was not possible even in recent history of the field.

Over the last decade, researchers have tried to improve their understanding of the functionality of human brain and machine diagnosis of mental illness. A large number of technique have been applied to learn about complex brain system and these techniques were intended to aid diagnosis and assessment of the extent of brain damage. Though hese techniques are able to detect damage to the brain, they are unable to provide the clear image in some circumstances. They have not the capacity to cover the entire brain rather provide a limited coverage of its parts. However, in the field of medical science especially in brain diagnosis research, there are various prominent techniques which have been studied and investigated to present promising diagnosis result. Functional and Diffusional magnetic resonance imaging are non-invasive techniques. These (fMRI and DMRI) advanced techniques have been used to investigate physiological disturbances and now developing leads to manifest psychiatric illness.

The purpose of this review paper is to examine existing techniques and to outline the types of challenges that can be addressed. To our knowledge, this review report represents the first effort to check impairment 
detection with an exact application on complex brain network. In this review, we do not consider any specific brain disorders. Rather, we aimed to identify the prominent techniques which have been applied to analyse complex brain networks based on the graph theory However, we found that many relevant tasks were mostly published in the area of neuroscience that we have focussed below. Therefore, we have elected to limit the scope of our review that can be focussed in future of neuroscience research.

The paper is organized as follows: Section 2 presents the review of related works and contributions, while the analysis of graph based complex brain network is discussed in section 3. We focus on Functional MRI as well as Diffusional MRI techniques in section 4. Finally, the guidance of future research directions and conclusion is provided in section 5 .

\section{Literature Review}

Van der Horn et al. (2017) Illustrated on mild Traumatic Brain Injury (mTBI) that is one of the most widespread disorders in neuroscience. They found that although the complaints of post-traumatic injury are reported frequently, a consistent solution has not yet been found. To gain a comprehensive understanding, they used graph theory analysis of complex interactions between complaints, functional brain networks, depression and anxiety in the sub-acute phase after mTBI. Several recent studies present a review of advances in neuroscience focusing on the graph based research on exact areas of brain connectivity. Del Etoile and Adeli (2017) presented a detailed outline of brain connectivity and graph theory analysis as a great solutions of Alzheimer's disease. McColgan et al. (2017) proposed that functional and structural brain network correlates as a possible solutions of Huntington's disease. Using resting state fMRI data they examined how different functional and structural brain networks chronicle to depressive affection in premanifest HD and advantageous controls and finally got significant results. Hart et al. (2016) discussed about human brain as the most powerful complex system and recently this idea of complex brain networks with graph theory has entered a new era in neuroscience. Using resting state fMRI they provided new ideas in brain mapping with graph applied to neurosurgery especially to traumatic brain injury.

Bullmore and Sporns (2009) reviewed and told that recent development of graph theory analysis has changed the dimension of complex brain network research. To achieve a complete understanding of complex brain network, they provided important information of measuring the brain network organization using functional MRI, structural MRI, diffusion MRI, EEG, MEG. Chen and Glover (2015) described functional MRI shown great direction to understand cognition in both healthy and dysfunctional brain. (Hart et al., 2016) used functional MRI with BOLD contrast imaging to generate better-recorded images. Bullmore and Sporns (2009) explained the quantitative analysis of complex networks using graph theory to improve the patterns of human brain complex networks.

Fox and Raichle (2007) believed that resting-state BOLD fMRI studies accept broadly acclimated functional connectivity to explore the alignment of functional networks. It can accomplish admitting indirect, strong, inferences about the functional access. Song et al. (2008; van den Heuvel et al., 2009; Zhou et al., 2007) examined that Many exploratory readings have inspected the record between the structures of the brain network from the point of appearance of graph theory and multiplicities of behavioural phenotypes in health and disease, including calibration scores, affliction continuance and genotypic variations (Liu et al., 2010; Glahn et al., 2010). Iannetti and Wise (2007; Honey et al., 2009) discussed that the functional connectivity from diffusion MRI will provide good complements for modelling functional networks. Moreover, they believed that although resting-state functional connectivity is mutable and is frequently present between regions without direct structural links, its strength, spatial statistics and tenacity are nevertheless controlled by the large-scale functional structure of the human cerebral cortex.

The major contributions of our survey paper are as follows, we aim to familiarize graph based study of complex brain network. We describe brain as a complex network and graph based methods can be applied to extract the features. In addition, we discuss many of the relevant works on graph based complex brain network that has been used to "real-world" scenarios for brain disorders. Finally, with these ideas established we then explain the contributions of functional and Diffusion MRI with brain connectivity. We discuss how these technologies can help ameliorate the future guidance of complex brain network research.

\section{Complex Brain Network Analysis}

Brain network consists of a number of elements including nodes and edges that are mutually interconnected to each other (Kabbara et al., 2016a). These systems are not monitored centrally rather it presents collective dynamics with self-organization (Fig. 1). Overall, a network is any system with sub-units that are linked into a whole.

For example, in social relationships, individual people indicates as nodes and it expresses as $\mathrm{V}$ and the joint relations between two nodes are indicating whether the corresponding peoples are accompanied or not. It's artlessly accurate as a bend as $E$. The groups of nodes and edges indicate together as a graph: $G=(V, E)$ (Thirion et al., 2006). 
a
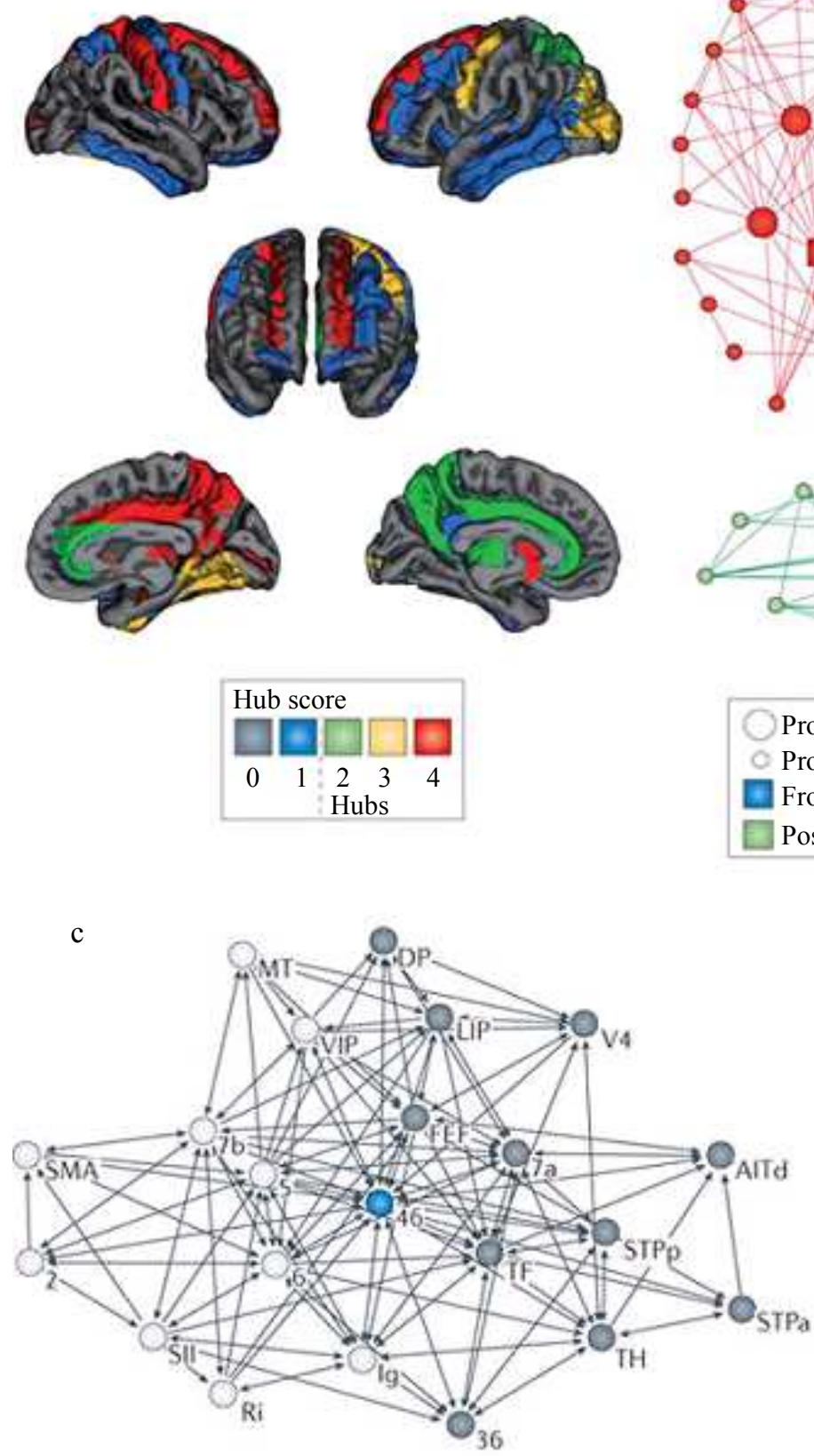

$\mathrm{b}$

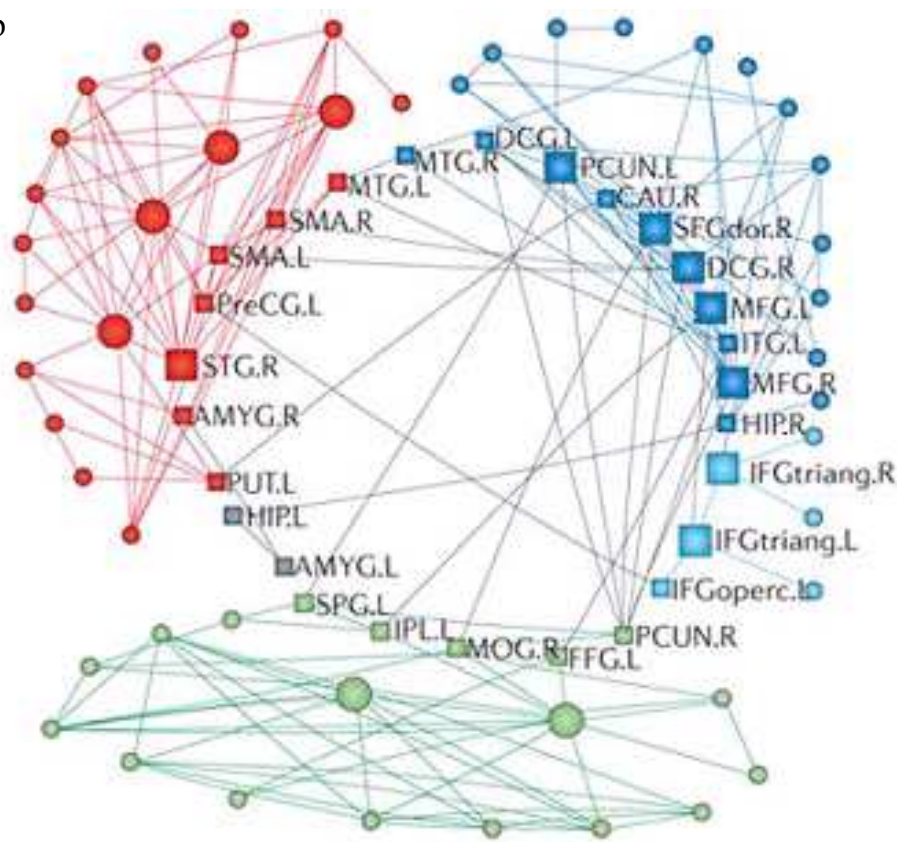

$\begin{array}{ll}\begin{array}{l}\text { Provincial hub } \\ \text { Provincial non-hub }\end{array} & \text { Connector hub } \\ \text { Frontoparietal module } & \square \text { Connector non-hub } \\ \text { Posterior module } & \square \text { Ventral module } \\ \text { Prefrontal module }\end{array}$

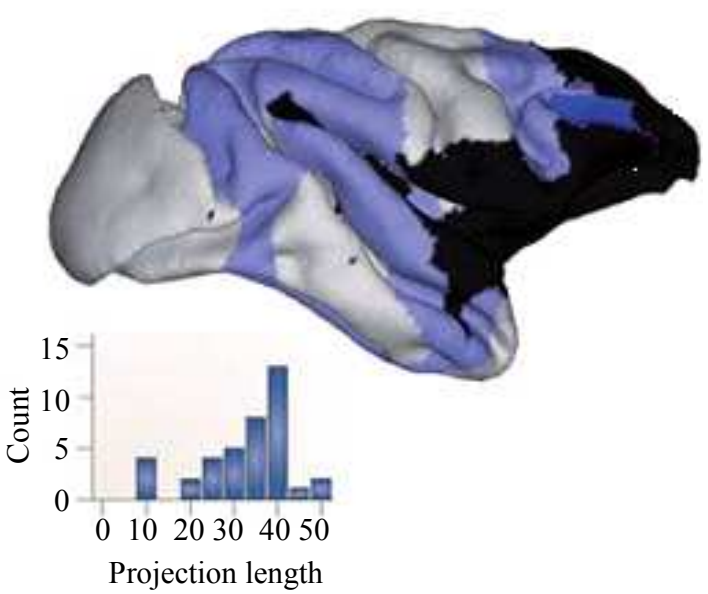

Nature reviwes| Neuroscience

Fig. 1: Complex brain network: Hubs and modules in the brain. Image courtesy of Bullmore and Sporns (2012)

The human brain is organized into complex system allowing within individual components by structurally and functionally. But compassionate its structure and action one of the absolute accurate challenges in neuroscience. To overcome the challenges in neuroscience, many techniques have developed and already applied to make sense of the bewildering complexity of this most mysterious structure.
From past decade, many researchers tried to find the patterns of structural and functional connectivity of brain network by accumulation an array of different imaging technologies like EEG, MEG and structural, functional, Diffusion MRI with adult analytic strategies such as vivo imaging, activating causal modelling, fractional atomic squares and structural graph modelling (Table 1) (Bullmore and Sporns, 2012). 
Table 1: Reviews of different automated disease diagnosis techniques applied to implement complex brain network analysis

\begin{tabular}{|c|c|c|c|c|}
\hline Techniques & $\begin{array}{l}\text { Application of } \\
\text { brain networks }\end{array}$ & Acquisition & Strengths & Weaknesses \\
\hline $\begin{array}{l}\text { Structural MRI } \\
\text { (Bullmore and } \\
\text { Sporns, 2009; } \\
\text { Guye et al., 2010; } \\
\text { Sporns, 2011; } \\
\text { Hagmann et al., 2007) }\end{array}$ & $\begin{array}{l}\text { Analyses of structural } \\
\text { covariance of morph- } \\
\text { ological measures (e.g., } \\
\text { cortical thickness or } \\
\text { volume) between brain } \\
\text { regions (high correlation } \\
\text { implies a network link) }\end{array}$ & $\begin{array}{l}\text { Single 3D volume of } \\
\text { the brain (e.g., T1 } \\
\text { MPRAGE), usually } \\
\text { acquired as standard } \\
\text { in most MRI protocols }\end{array}$ & $\begin{array}{l}\text { Simple to acquire } \\
\text { and not limited by } \\
\text { artefacts to the same } \\
\text { degree as other } \\
\text { MRI-based } \\
\text { sequences }\end{array}$ & $\begin{array}{l}\text { Limited by degree of } \\
\text { infe-rence one can } \\
\text { deduce based on } \\
\text { cortica measures }\end{array}$ \\
\hline $\begin{array}{l}\text { Functional MRI } \\
\text { (Bullmore and } \\
\text { Sporns, 2009; } \\
\text { Guye et al., 2010; } \\
\text { Wang et al., 2010; } \\
\text { Maihöfner } \text { et al., 2005) }\end{array}$ & $\begin{array}{l}\text { Analyses of statistical } \\
\text { dependencies between } \\
\text { brain regions. }\end{array}$ & $\begin{array}{l}\text { Specific } 4 \text { D sequence } \\
\text { sensitive to BOLD } \\
\text { contrast reflecting } \\
\text { hemodynamic response } \\
\text { of neuronal activity }\end{array}$ & $\begin{array}{l}\text { Reasonably high } \\
\text { temporal and good } \\
\text { spatial resolution }\end{array}$ & $\begin{array}{l}\text { An indirect measure } \\
\text { of neuronal activity. } \\
\text { Significant artefacts } \\
\text { require careful } \\
\text { pre-processing }\end{array}$ \\
\hline $\begin{array}{l}\text { Diffusion MRI } \\
\text { (Iturria-Medina et al., } \\
\text { 2008; Li et al., 2009) }\end{array}$ & $\begin{array}{l}\text { Uses reconstruction of } \\
\text { tracts to imply } \\
\text { structural connectivity } \\
\text { between brain regions }\end{array}$ & $\begin{array}{l}\text { Measures free water } \\
\text { diffusion. }\end{array}$ & $\begin{array}{l}\text { Suggests a clear } \\
\text { relationship with } \\
\text { underlying structural } \\
\text { and functional brain } \\
\text { connectivity. }\end{array}$ & $\begin{array}{l}\text { Variations in } \\
\text { sequences and } \\
\text { algorithms can } \\
\text { significantly affect } \\
\text { network para-meters. }\end{array}$ \\
\hline $\begin{array}{l}\text { PET } \\
\text { (Bullmore and } \\
\text { Sporns, 2009; } \\
\text { Maihöfner } \text { et al.,2005; } \\
\text { Power } \text { et al., 2011; } \\
\text { Debaere } \text { et al., 2001) }\end{array}$ & $\begin{array}{l}\text { Covariance in glucose } \\
\text { metabolism bet-ween } \\
\text { regions }\end{array}$ & $\begin{array}{l}\text { Injection of a } \\
\text { radioisotope followed } \\
\text { by detection of gamma } \\
\text { rays }\end{array}$ & $\begin{array}{l}\text { It is a good } \\
\text { biomarker for } \\
\text { Alzheimer's dis-ease } \\
\text { and provides direct } \\
\text { metabolic data }\end{array}$ & $\begin{array}{l}\text { Radiation, limits on } \\
\text { repeatability. } \\
\text { Potentially lower } \\
\text { spatial resolution. }\end{array}$ \\
\hline $\begin{array}{l}\text { EEG } \\
\text { (van Straaten and } \\
\text { Stam, 2013; } \\
\text { Rubinov and Sporns, } \\
\text { 2010; Boersma et al., } \\
\text { 2011; de Haan } \text { et al., } \\
\text { 2009; Hassan et al., } \\
\text { 2017a) }\end{array}$ & $\begin{array}{l}\text { Measures statistical } \\
\text { dependency between all } \\
\text { pair wise combinations } \\
\text { of cha-nnels, often in } \\
\text { multiple frequency bands }\end{array}$ & $\begin{array}{l}\text { To measure electrical } \\
\text { signals in the brain } \\
\text { directly it uses } \\
\text { electrodes. }\end{array}$ & $\begin{array}{l}\text { Direct measure of } \\
\text { neuronal currents } \\
\text { and best temporal } \\
\text { resolution. }\end{array}$ & $\begin{array}{l}\text { Due to skull and scalp } \\
\text { it has some impor- } \\
\text { tant limitations and } \\
\text { distortion. }\end{array}$ \\
\hline $\begin{array}{l}\text { MEG } \\
\text { (van Straaten and } \\
\text { Stam, 2013; } \\
\text { Rubinov and Sporns, } \\
\text { 2010) }\end{array}$ & $\begin{array}{l}\text { Measures statistical } \\
\text { dependency between all } \\
\text { pairwise combi-nations } \\
\text { of channels }\end{array}$ & $\begin{array}{l}\text { To measures magnetic } \\
\text { field alterations using } \\
\text { magneto-meter }\end{array}$ & $\begin{array}{l}\text { Exceptionally high } \\
\text { temporal re-solution } \\
\text { but limited spatial } \\
\text { resolution (particularly } \\
\text { subcortical) }\end{array}$ & $\begin{array}{l}\text { Difficulties with } \\
\text { focusing signal } \\
\text { spatially and for low } \\
\text { signal-to-noise ratio }\end{array}$ \\
\hline
\end{tabular}

\section{Graph Based Analysis of Complex Brain Network}

Graph is simple model of complex structures, define as a set of nodes and edges which can be represented as $G=(V, E)$ (Fig. 2). This method have become a great tool in the field of technological, biological and amusing sciences such as the science of ecological networks, the World Wide Web, amusing networks and neuroscience. Onias et al. (2014) described that a network is a way to code a set of elements together with their connections. The elements are identified as nodes and their connections are identified as edges. When two nodes are connected by an edges, they are considered neighbours. In addition, edges can be categorized as directed, undirected and weighted (Fig. 3 and Fig. 4).

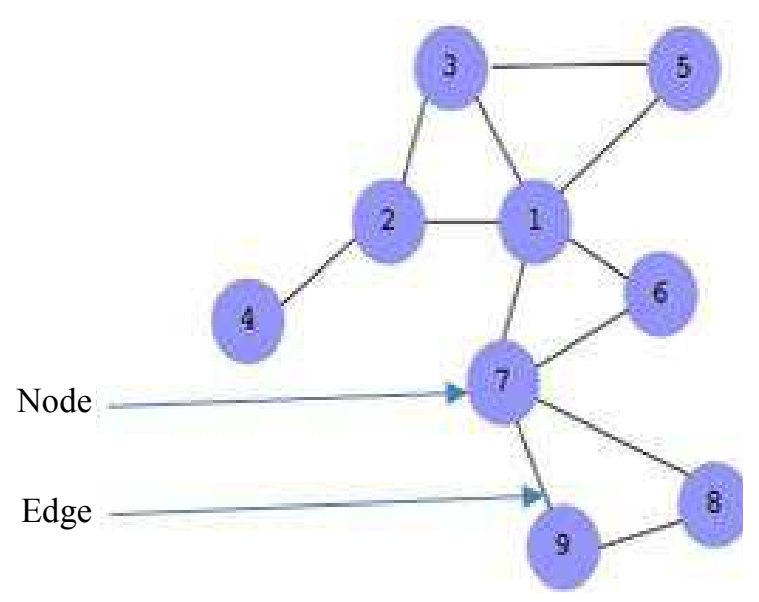

Fig. 2: Graphical representation of graph 


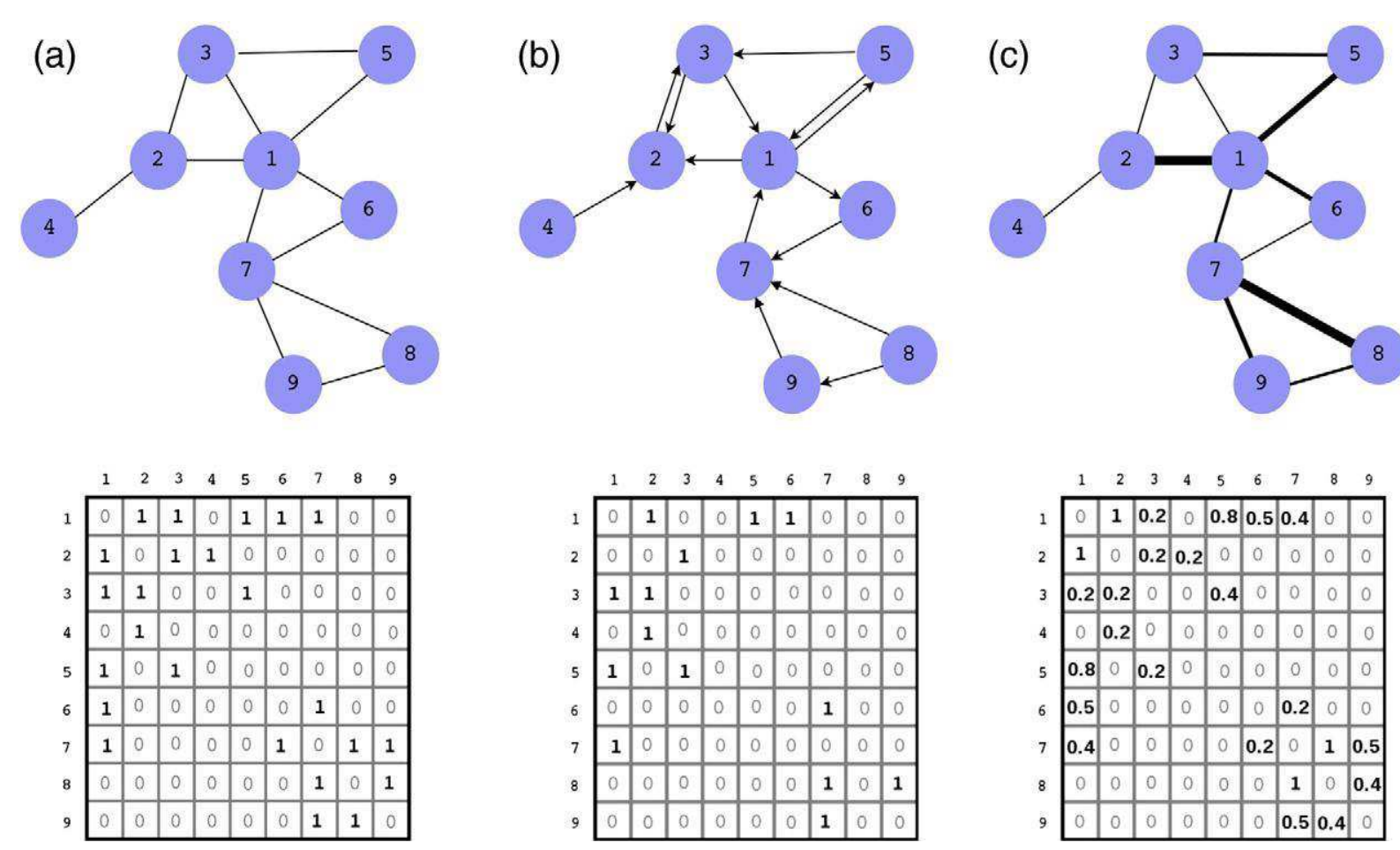

Fig. 3: Examples of (a) undirected, (b) directed and (c) weighted networks (top row) and their corresponding adjacency matrices, coded with a gray-scale colour map (bottom row). Image courtesy of (Onias et al., 2014)

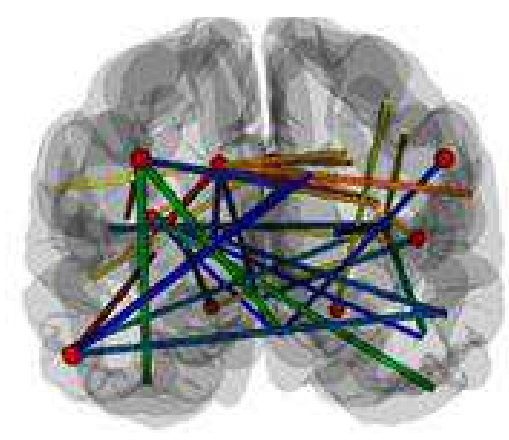

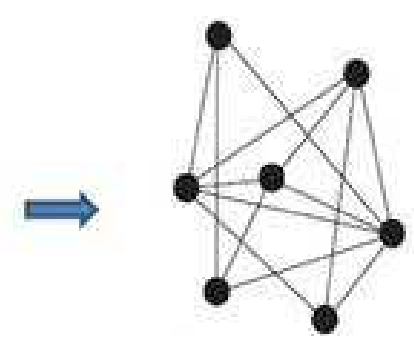

(a)

Undirected graph

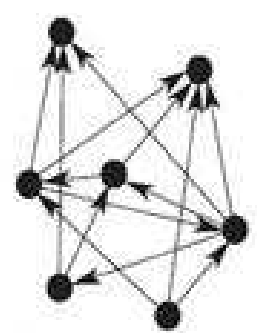

(b)

Directed graph

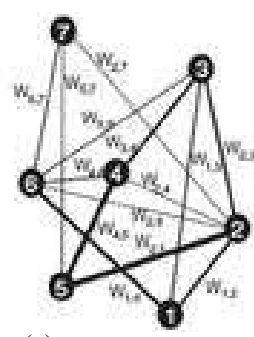

(c)

Weighted graph

Fig. 4: Examples of complex brain network based on graph. Image courtesy of (Boccaletti et al., 2006; Fallani et al., 2014)

Moreover, a network framework with $\mathrm{N}$ nodes is said to accept labels $\mathrm{N}$ that assigns a representation (weight) to each link is called weighted network. Otherwise, if the links of a network do not accept labels, the system is named unweighted network. Previously described that the brain can be seen as a complex network: An affiliated network area where nodes represent different specialized regions and edge represent advice pathways. From the functional viewpoint, communication is coded by temporal dependence between the activities of different brain areas. The use of graph based technique in translational neuroscience has become great to measure brain dysfunctions in agreement of anomalous reconfiguration of brain networks. Besides, graph theory analysis of brain networks can be blindly activated to brain signals. The adversity with integrating data from multiple modalities is that it is computationally actual ambitious to analyse and it is acutely difficult to anticipate anticipate the relationships between objects in the data (Fallani et al., 2014).

\section{Brain Network Connectivity}

The human brain is organized by structurally and functionally and it is one of the most complex systems. Brain connectivity may be analysed and considered application as a broad range of network analysis methods and categorized as: Structural connectivity and functional connectivity (Fig. 5) (Ciric et al., 2016). 


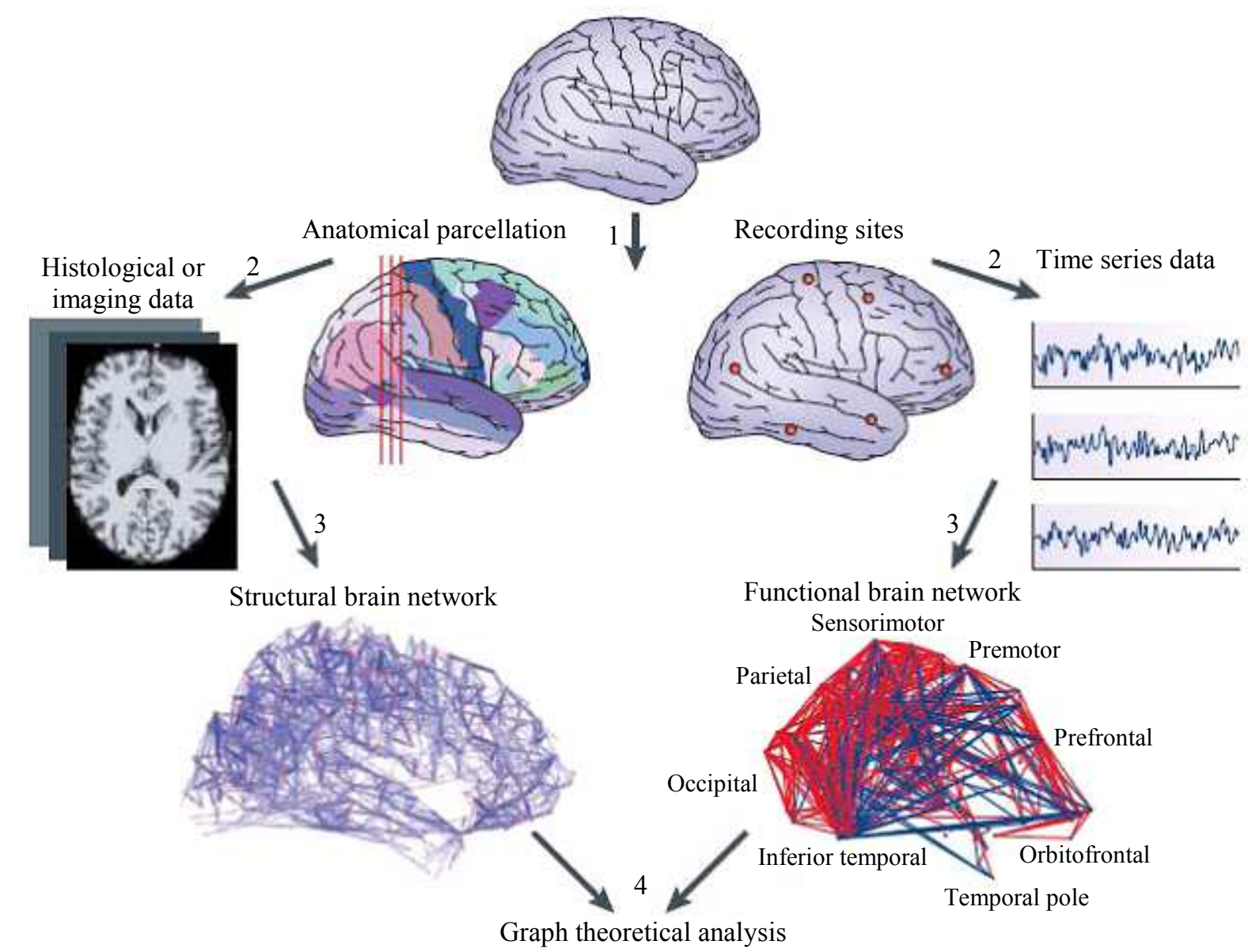

Fig. 5: Graph theory analysis of functional and structural brain network can be shown through the subsequent four phases. First, establish the network nodes. Second, Estimate connected admeasurements of affiliation between nodes. In third, Generate a connection cast by accumulation all pairwise links between nodes. In fourth, analyse the parameters of brain networks. Image courtesy of (Bullmore and Sporns, 2009)

Many of the brain connectivity methods are already activated in alongside efforts to map and call added biological systems, e.g., those of cellular metabolism, ecology or gene regulation. The approach of directed graphs is one of the most popular methods to map networks of structural and functional brain connectivity at all stages.

Graphs are collection of nodes and edges which are corresponding to brain regions and pathways. In the easiest form, graphs can be declared by a connection matrix with binary elements that identify the existence or lack of a directed edge between pairs of nodes. Generally, nodes can connect with other nodes through indirectly or directly. Indirect interaction is a connection of multiple edges and the functional effectiveness of these indirect connections are depends on the path length. Besides the distance between two nodes are corresponding to the length of the shortest path and the all-around average of all distances is called the path length.

According to formal outline of graph based analysis, complex brain network consists of a set of structural and functional connectivity and can be processed by the following several steps.

\section{Structural Brain Network Connectivity}

Structural brain connectivity represents the structural associations a part of altered neuronal elements including both the morphometric alternation and accurate anatomical connectivity. At the complex brain networks, this access about accredits to white amount projections bond cortical and subcortical regions. The structural connectivity of human brain in vivo can be completed by structural and diffusion MRI. (Bullmore and Sporns 2009; Van der Horn et al., 2017). Structural connectivity of this affectionate is anticipate to be almost abiding on under time scales (seconds to minutes) but only some of artificial experience-dependent variations at best time scales (hours to days) (Friston et al., 1993). In addition, in the field of neuroimaging, as the directionality of projections currently cannot be detected, the structural brain connectivity is mostly abstinent as a set of accidental relations. 


\section{Functional Brain Network Connectivity}

Functional brain connectivity denotes the functional relations of brain areas accepting by quantifying the temporal correlations between spatially limited neurophysiological contest from fMRI and EEG/MEG data (Friston et al., 1993; Kabbara et al., 2016b). It is largely derived from time series analysis of complex brain networks because it is highly time-dependent and describes patterns of statistical reliance among neural elements (nodes and edge) (Joo et al., 2016; Zhang et al., 2017). A various number of neuroimaging techniques, including diffusion MRI, functional MRI, Electroencephalography (EEG), Magnetoencephalography (MEG) may be applied to analyze time series data of functional brain connectivity and can be figure out in a number of ways, including as spectral coherence, mutual information, or cross-correlation.

The future indications of functional brain connectivity is to apply an algorithm in time-evolving graphs, where the challenging factors are to extract features and to find patterns incrementally over time. Another indication of brain connectivity is if the functional brain connectivity features are extracted from the neuroimaging data, graph based techniques can be further applied to complex brain networks and examine their essential topological properties to detect abnormalities.

\section{Role of Imaging Techniques for Complex Brain Network Analysis}

Graph based analysis of complex brain networks have given significant output to find a variety of brain and mental disorders. Functional and Diffusion MRI has given rise to rich and flexible structure function relationships of complex brain network analysis. Besides these imaging techniques already contributed to developing better diagnoses and treatment options of neurodegenerative disorders like as Schizophrenia disease, Alzheimer's disease, traumatic brain injury, Epilepsy, Parkinson's disease etc., Sporns (2014). However, the studies and major contributions of functional and diffusion MRI for complex brain network analysis based on graph provides are as follows.

\section{Funtional Magnetic Resonance Imaging (fMRI)}

Functional MRI has released an important window for the non-invasive analysis of the circuitous human brain. Because it can evaluate different brain regions over times, which is the basic need to consider the brain network as a complex system. Functional MRI is a neuroimaging procedure using MRI method that measures brain activity to detect changes in blood flow.
Functional MRI is also known as Blood Oxygenation Level Dependent (BOLD) MRI which is one of the most great technique to recognize activity in the human health and brain (Matthews and Jezzard, 2004). BOLD fMRI was first developed and described in 1989. It has rapidly developed as a non-invasive method to map brain activities. Although a number of methods have been applied to measure functional brain networks connectivity, functional Magnetic Resonance Imaging (fMRI), especially resting state fMRI has played great rules for identifying clinical biomarkers for brain diseases (Rodic and Zhao, 2015; Song and Jiang, 2012).

\section{Basic Goals and Current Applications of Functional MRI}

Functional MRI is a well-developed imaging technique to detect changes in the signals used to produce magnetic resonance images that are linked with neuronal action in the brain. Besides, it can be advised to abide specific hypotheses apropos the attributes of the broadcast systems amenable for assorted anatomic/functional responses of the brain. Hennig et al. (2003; Gore, 2003) illustrated that although many of the imaging techniques have been used to detect the brain disorder, fMRI covers all domain of systemic neurosciences. Functional MRI is just about to enter the domain of clinical applications. Daimiwal et al. (2012; Hennig et al., 2003) described that functional magnetic resonance imaging techniques have confirmed to be vital to understand the functional, cellular and molecular mechanisms of the brain (Daimiwal et al., 2012).

\section{Advantages and Limitations of Functional MRI}

The benefit of fMRI is that it is non-invasive and doesn't use radiation like Computed Tomography (CT) Positron Emission Tomography (PET) and X-rays scans. It can evaluate brain function securely and efficiently. Virtually fMRI has no risks. Besides, it is analogously cheap, as no trace or adverse appropriate and easy to use. Functional Magnetic Resonance Imaging (fMRI) can produce are very high-resolution images. Also, fMRI is far more objective to compare with the other traditional questionnaire methods of psychological evaluation. Although fMRI has many advantages yet it has some difficulties. First, it is costly. Second, it can alone abduction bright images contrarily its imaging action may abduction exceptionable artefacts. Third, it is an aberrant admeasurement of academician action that may be suffered by non-neural changes in the body and fourth, advisers still don't absolutely accept how it works (Chen and Glover, 2015; Ahsan et al., 2009). In addition the goals and clinical applications of fMRI are listed in Table 2. 
Table 2: The goals and clinical applications of fMRI based on graph theory

\begin{tabular}{|c|c|c|c|c|}
\hline Techniques & Goals & Applications of fMRI & Graph used & References \\
\hline \multirow[t]{10}{*}{ Functional MRI } & $\begin{array}{l}\text { Examine the structure } \\
\text { of the complex } \\
\text { brain networks. }\end{array}$ & $\begin{array}{l}\text { Aging and } \\
\text { Alzheimer's disease. }\end{array}$ & $\sqrt{ }$ & $\begin{array}{l}\text { Bullmore and Sporns (2009; } \\
\text { Achard and Bullmore, 2007; } \\
\text { Meunier et al., 2009; } \\
\text { Supekar } \text { et al., 2008; } \\
\text { Buckner } \text { et al., 2009; } \\
\text { Buckner et al., 2009; } \\
\text { Hata } \text { et al., 2016) }\end{array}$ \\
\hline & $\begin{array}{l}\text { Clearly, determine which } \\
\text { part of the brain is handling } \\
\text { critical functions including } \\
\text { speech, thought, movement } \\
\text { and sensation are called } \\
\text { brain map-ping. }\end{array}$ & $\begin{array}{l}\text { Relationship of } \\
\text { Carotid stenosis. }\end{array}$ & $\sqrt{ }$ & Chang et al. (2016) \\
\hline & $\begin{array}{l}\text { Help assess the effects } \\
\text { of disease on brain } \\
\text { function. }\end{array}$ & In migraine. & $\sqrt{ }$ & Colombo et al. (2015) \\
\hline & $\begin{array}{l}\text { Investigating the growth } \\
\text { and function of brain } \\
\text { connectivity. }\end{array}$ & $\begin{array}{l}\text { Traumatic Brain } \\
\text { injury. }\end{array}$ & $\sqrt{ }$ & $\begin{array}{l}\text { van der Horn et al. (2017; } \\
\text { Hart et al., 2016; } \\
\text { Nakamura } \text { et al., 2009) }\end{array}$ \\
\hline & $\begin{array}{l}\text { Monitor the developments } \\
\text { of surgery, radiate-on }\end{array}$ & Parkinson's disease & $\sqrt{ }$ & $\begin{array}{l}\text { Gao and } \mathrm{Wu}(2016 ; \\
\text { Hassan } \text { et al., 2017b) }\end{array}$ \\
\hline & $\begin{array}{l}\text { therapy, or other surgical } \\
\text { actions for the complex }\end{array}$ & $\begin{array}{l}\text { Pearson correlation } \\
\text { of brain disorder. }\end{array}$ & $\sqrt{ }$ & Wang et al. (2017) \\
\hline & brain networks. & Drug addicts & $\sqrt{ }$ & $\begin{array}{l}\text { Nakamura et al. (2009; } \\
\text { Liu et al., 2009) }\end{array}$ \\
\hline & & Hyperactivity disorder. & $\sqrt{ }$ & Wang et al. (2009) \\
\hline & & Schizophrenia disease. & $\sqrt{ }$ & Liu et al. (2008) \\
\hline & & Epilepsy disease. & $\sqrt{ }$ & Liao et al. (2010) \\
\hline
\end{tabular}

\section{Brain Network Connectivity with Functional MRI}

According to the graph theory concepts brain networks connectivity can be articulated as a graph $G=(V, E)$ area where $\mathrm{V}$ can be the accumulating of nodes absorption the academician regions and $\mathrm{E}$ can be the anatomic access amid these brain regions. van Den Heuvel et al. (2009; van Straaten and Stam, 2013) explored a schematic amount of a graph symbol of the functional brain network in (Fig. 6).

Hagmann et al. (2007; Valencia, et al., 2009; Meunier et al., 2009) studied about the resting-state fMRI for measuring of the functional brain network. They also told that the functional brain networks interactions between regions are abundant because it has an intrinsically cohesive modular (community) structure and functionally linked with brain regions. Nakamura et al. (2009) illustrated that the topological properties (connectivity strength, small-world attributes) of functional brain networks at individual time points through the recovery from traumatic brain injury had changed using graph based resting fMRI. Liao et al. (2010) showed that graph based resting-state fMRI analysis of functional brain networks in epilepsy was related with smaller clustering coefficients and shorter path lengths. Liu et al. (2008) provided the first graph based analysis of functional brain networks in schizophrenia using resting fMRI and also showed that several topological measurements, like local efficiency, global efficiency and clustering coefficient. Supekar et al. (2008) reported that the unusual small-world group in functional brain networks was first demonstrated by applying resting state fMRI in Alzheimer's disease. Wang et al. (2009) discussed the deficit hyperactivity condition are associated with the unusual small-world topology in functional brain networks.

In Addition, several fMRI studies have examined age-related variations in the functional forms of the brain utilizing graph-based network models. Fair et al. (2009) reported that using a fMRI dataset (210 individuals: 66 aged 7-9 years; 53 aged 10-15 years; 91 aged 19-31 years), functional brain networks composed of 34 predefined brain areas were connected over age by the small-world measurements. In contrast, Supekar et al. (2009) reported that module assignments change over age because the progress of brain networks can be considered by an abrasion of short-range functional connectivity and a deepening of all-embracing anatomic connectivity. So, this suggests a dynamic developmental trajectory of brain functional network topology. 




Fig. 6: The model of functional brain network consists of nodes and edges between regions that are functionally affiliated and can be bidding as a circuitous graph. In the console (a), the accumulating of nodes is represented and these can be brain regions. In the console (b), the actuality of functional interactions between the nodes in the network needs to be clear, because it represents the level of interactions between different nodes of the network. In the console (c) the actuality of interactions amid two nodes can be identified as for whether their similar of functional interactions exceeds an assertive predefined threshold. This after-effect in modelling the brain as a functional network with linked between different areas that are functionally connected. Image courtesy of (Guye et al., 2010)

Achard and Bullmore (2007) showed that in older adults, the interregional connectivity of functional brain networks derived from resting fMRI had reduced efficiency than in young adults. Wang et al. (2017) studied of Functional Brain Network (FBN) and have been introduced depression disorder classification including Pearson correlation, extracting features from constructed FBN where functional MRI shown a successful impact. To address these challenging issues they have developed a method using a sparse low-rank model to automatically remove weak relationship of FBN.

Several recent studies have shown that in the context of behaviour, development and disease states functional connectivity has proven a powerful method for analysing complex brain networks measuring by resting-state fMRI. Warren et al. (2017) applied functional brain connectivity to structural brain connectivity to eliminate functional connectivity with other brain regions measuring derived from the fMRI BOLD signal. Goelman et al. (2017) described an analysis method by using frequencies and phase of resting-state functional
MRI data that have shown the correlation between coupled time-series functions. Besides they illustrated that this analysis can be applied to any coupled functions in numerous areas containing electrophysiology, EEG or MEG in neuroscience research. Xu et al. (2016) discussed Borderline Personality Disorder (BPD) neuroimaging research that has to appear structural and functional deviations in brain networks. To accept the topological backdrop of academician networks, they active blueprint approach by investigating anatomic alluring Resonance Imaging (fMRI) data. Although the additional a lot of accepted neurodegenerative ataxia is Parkinson's ache (PD) primarily affecting the aging populations, its neurophysiological mechanisms still unclear.

Gao and $\mathrm{Wu}$ (2016) proposed that the development of neuroimaging techniques can be allowed to detect Parkinson's Disease (PD) in patients. Especially they described the functional MRI neuroimaging technique for detecting of the functional connectivity of brain networks in patients with Parkinson's Disease (PD). Traumatic Academician Injury (TBI), after-effects from 
accident to academician tissue acquired by an external force. The neurobiological mechanisms of Traumatic Brain Injury (TBI) underlying specific disorders still are not fully clear. Several of the neuroimaging techniques have been applied to detect these disorders. To find a clear image, Diffusion MRI, Diffusion tensor imaging and Functional MRI provided new insights of the animal academician in both health and disease focussing on structural and functional connectivity patterns. Xiao et al. (2015) identified several studies that many of functional connectivity abnormalities in brain networks, but researchers are still working to identify abnormalities. Colombo et al. (2015) discovered functional connectivity abnormalities in migraine by resting-state fMRI which is a new field of neuroscience research. Because, to explore the functional connectivity of brain areas, resting-state fMRI is one of best methods.

Functional brain connectivity is a relatively new research topic in the field of complex brain networks. Several studies found that the function of brains can be changed by aging and Alzheimer's Disease (AD) and shown recent innovations neuroimaging techniques have detected abnormalities in functional networks. To detect diseases and analyse functional connectivity Dennis and Thompson (2014) applied three primary methods including seed-based, ICA and graph theory. In the field of neuroscience, especially in brain complex network graph theory is playing a great role. Chang et al. (2016) identified that Carotid stenosis changes the functional connectivity and decline the cognitive functions. To evaluate the relationships between hemodynamic injury and cognitive decline, they applied graph theory based on resting state fMRI.

\section{Diffusion Magnetic Resonance Imaging (DMRI)}

Diffusion MRI uses the diffusion of water molecules to generate contrast in MR images. Although over the last 30 years various technologies have been developed to detect physiological illness, Diffusion MRI has become an accustomed address with an abundant appulse on bloom affliction and neurosciences (Gallichan, 2017). From the mid-1980s, Diffusion MRI is as well-known as DiffusionWeighted Magnetic Resonance Imaging (DWI or DWMRI) (Delouche et al., 2016; Le Bihan et al., 2006).

\section{Goals and Current Applications of Diffusion MRI}

Diffusion MRI is a quickly establishing the experimental tool for the evaluation of brain diagnosis. Its goal is to examine the white matter in the brain and to determine diffusion coefficient in-vivo which has great potential for further understanding of normal and abnormal physiology (Bammer, 2003; Mori and Barker, 1999). Recently, Diffusion MRI is an imperative technique that already widely used for the study of stoke and other neuroimaging disorders. This technique is very important to apprehend the baptize circulation in academician which allows us to abstraction academician fibre structures (Mori and Barker, 1999; Booth and Hamarneh, 2010; Mueller et al., 2015). The applications of Diffusion MRI in brain disorder and clinical neuroscience which are summarized in Table 3.

\section{Advantages and Limitations of Diffusion MRI}

Diffusion alluring Resonance Imaging (DMRI) is one of a lot of rapidly developing diagnosis tools in the field of MRI which image adverse is based on the circulation of baptizing molecules in tissue. Besides, Circulation MRI can appraise white amount in the brain. As DMRI has been activated to studies of brain disorders so it can have some advantages and limitations (Table 4) (Jones, 2010; Chenevert et al., 2000).

\section{Brain Network Connectivity with Diffusion MRI}

Kahn et al. (2017) described that to allow for actual information transmission, human expertise learning has to need to fine-scale coordination of distributed networks of brain areas associated with white matter tracts. For testing this hypothesis they collected structural imaging data and to identify streamlines linking cortical and subcortical brain areas, they used deterministic tractography which has made structural networks for each participant. Finally, they decided that enlarged white matter connectivity linking early visual areas was related with a faster learning level.

Hagmann et al. (2007) proposed that mapping of the structural brain network connectivity with circulation MRI is an action fabricated of four accomplish which apparent in beneath (Fig. 7). First, they acclimated Circulation Spectrum MRI (DSI) which is performed on a sample abstracts set. This accretion provided a $3 \mathrm{D}$ circulation action at anniversary abode in the brain. This abstracts set is alleged a circulation map. It is formed by the bounded tissue features, in accurate by the acclimatization of axonal bundles absolute in the brain. Second, based on this map they generated an amount of 3D curves (called fibres) that followed the aisle laid by the white amount axonal bundles. Third, alone from the beforehand step, they acclimated a heuristic that far the academician white matter gray amount interface into baby zones of according apparent (called Regions Of Interest-ROIs) accoutrement the accomplished case and abysmal bookish nuclei boundaries. In the fourth step, they abutting the achievement of accomplishing two and three: The ROIs become nodes and the fibres are adapted into edges in the consistent graph. Finally, they appropriate that this blueprint estimates the body of white amount access amid any two regions of gray matter. 
Table 3: Applications of diffusional MRI based on graph

\begin{tabular}{|c|c|c|c|}
\hline Technique & Applications of DMRI & Graph used & References \\
\hline \multirow[t]{9}{*}{ Diffusion MRI } & $\begin{array}{l}\text { Diffusion Tensor Imaging (DTI) } \\
\text { in brain development. }\end{array}$ & $\sqrt{ }$ & $\begin{array}{l}\text { Hüppi and Dubois (2006; Neil et al., } \\
\text { 2002; Vakhtin et al., 2013) }\end{array}$ \\
\hline & Diffusion in acute stroke. & $\sqrt{ }$ & $\begin{array}{l}\text { van Gelderen et al. (1994; } \\
\text { van Everdingen et al., 1998; } \\
\text { Warach et al., 1995; Kamalian et al., 2011) }\end{array}$ \\
\hline & $\begin{array}{l}\text { Diffusion in chronic stroke and } \\
\text { small vessel disease. }\end{array}$ & $\sqrt{ }$ & $\begin{array}{l}\text { Wardlaw et al. (2013; Schaefer et al., } \\
\text { 2000; Hachinski et al., 2006) }\end{array}$ \\
\hline & Diffusion imaging in brain tumors. & $\sqrt{ }$ & $\begin{array}{l}\text { Hachinski et al. (2006; Holodny and } \\
\text { Ollenschlager, 2002; Maier et al., 2010; } \\
\text { Provenzale } \text { et al., 2006) }\end{array}$ \\
\hline & $\begin{array}{l}\text { Diffusion tensor MRI in } \\
\text { multiple sclerosis. }\end{array}$ & $\sqrt{ }$ & Rovaris and Filippi (2007; Li et al., 2013) \\
\hline & Diffusion MRI in Epilepsy. & $\sqrt{ }$ & $\begin{array}{l}\text { Bullmore and Sporns (2009; Govindan and } \\
\text { Chugani, 2010; Engel Jr. et al., 2013; } \\
\text { Arfanakis et al., 2002) }\end{array}$ \\
\hline & $\begin{array}{l}\text { DTI and Tractography in } \\
\text { neurosurgical planning. }\end{array}$ & & Clark and Byrnes (2008) \\
\hline & Diffusion MRI in psychiatric disorders. & $\sqrt{ }$ & $\begin{array}{l}\text { White } \text { et al. (2008; } \\
\text { Johansen-Berg and Behrens, 2013) }\end{array}$ \\
\hline & $\begin{array}{l}\text { DTI in crumbling (Aging) and age } \\
\text { related neurodegenerative disorders. }\end{array}$ & $\sqrt{ }$ & $\begin{array}{l}\text { Sullivan and Pfefferbaum (2011; } \\
\text { Brown et al., 2011; Sun et al., 2012) }\end{array}$ \\
\hline
\end{tabular}

Table 4: Advantages and Limitations of diffusion MRI

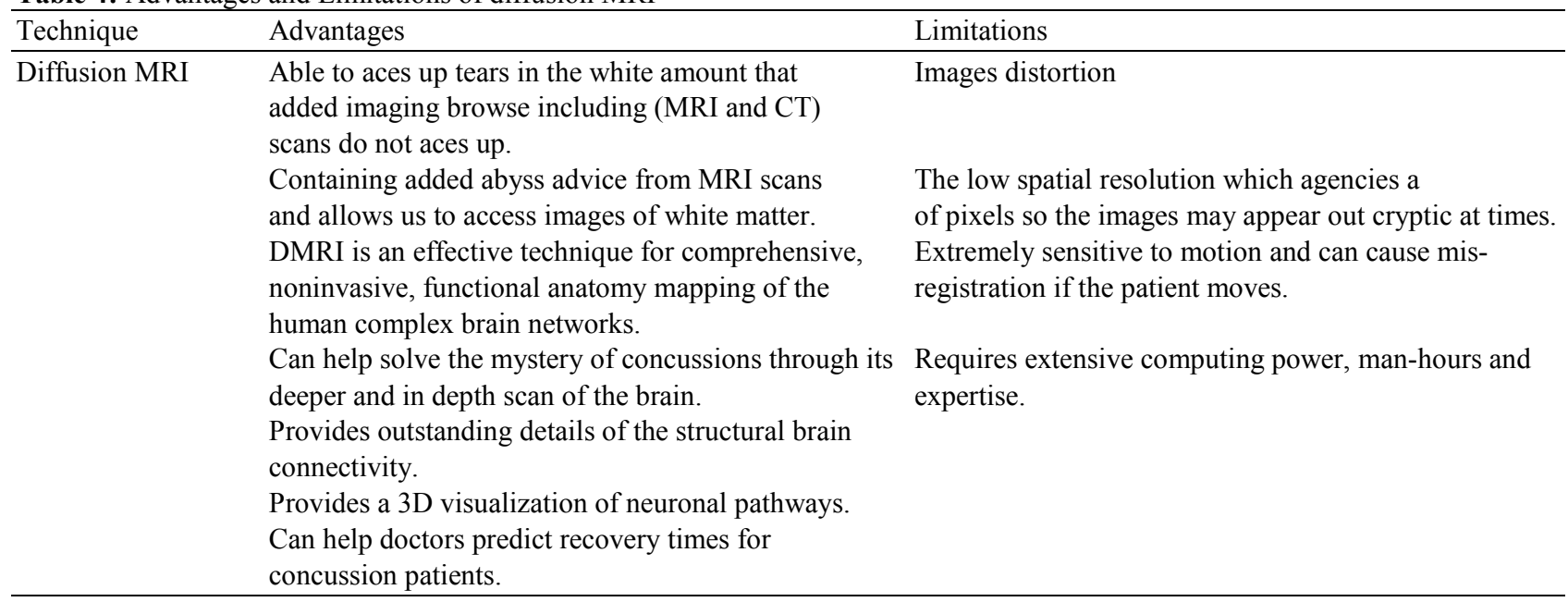

Structural brain connectivity mapping techniques are playing a very significant role to identify abnormal connectivity in psychiatric and neurologic disease, particularly Small animal connectivity techniques are very important to find anomalies in the disease model . Calabrese et al. (2015) showed small animal diffusion tractography that can be significantly improved through the groupings of ex vivo MRI with exogenous adverse agents, containing with innovative diffusion accretion and face-lifting address and probabilistic fibre tracking.

Schultz et al. (2016) illustrated, although many of the researchers has been studied an affluence of research into brain connectivity, we are far from a complete understanding to change over the development of human brain. They studied and described Computational Diffusion MRI to insights into human brain development. They have presented some recent findings on academician connectivity in autism, 22q11.2 abatement syndrome, Fragile X, Turner syndrome, Williams's syndrome and ADHD. Mostly they have been focused to find the features of brain networks development and biological methods engaged for detecting brain impairment. The study of brain mapping connectivity is still in its infancy. For imaging and analyzing brain connections. Li et al. 
(2016) proposed Diffusion Magnetic Resonance Imaging which noninvasively maps academician connectivity at an arresting calibration by barometer baptize molecules. Besides in recent years, there has been studied a lot on network modeling of brain connectivity seriously. Analyzing human brain networks, many of the researchers applied graph theory by using a various number of imaging techniques including functional MRI, Structural MRI, diffusion MRI and EEG/MEG separately.

$\mathrm{He}$ and Evans (2010) studied all of these techniques and shown many crucial properties of complex brain networks which can be applied to detect the abnormalities of brain regions especially focusing on Alzheimer's and Schizophrenia disease. To map the structural access of the human brain, Thomas et al. (2014) proposed Tractography based on diffusion-weighted MRI (DWI) which is one of the most prominent widely used technique. Besides, to investigate they applied this method and showed the highest sensitivity. Overall, for developing brain network analysis with fMRI and DMRI, different authors applied different software packages. The number of software packages for brain network analysis with fMRI and DMRI are listed in Table 5.

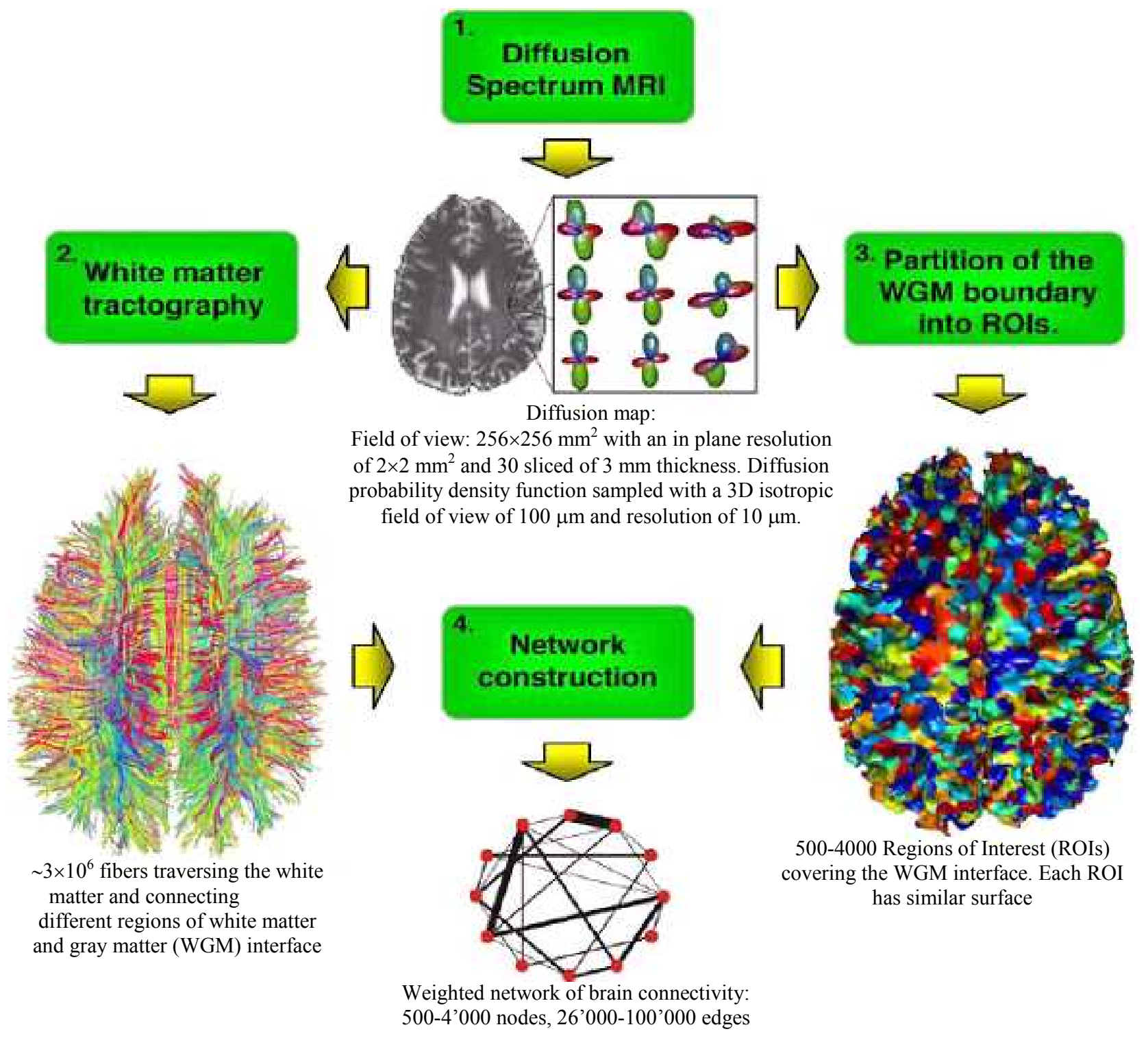

Fig. 7: Structural Brain network connectivity with diffusion MRI. Image courtesy of (Sporns, 2011) 
Table 5: Review of different Software packages for brain network analysis with fMRI and DMRI

\begin{tabular}{|c|c|c|c|c|}
\hline $\begin{array}{l}\text { Package } \\
\text { name }\end{array}$ & Descriptions & Category & Website & Refs. \\
\hline$\overline{\text { SPM }}$ & $\begin{array}{l}\text { SPM has been designed for the analysis } \\
\text { of brain imaging data sequences. The } \\
\text { current release of SPM is designed } \\
\text { for the analysis of fMRI, PET, SPECT, } \\
\text { EEG and MEG. }\end{array}$ & $\begin{array}{l}\text { Segmentation, time domain } \\
\text { analysis, spatial transformation, } \\
\text { statistical operation, } \\
\text { haemodynamic response. }\end{array}$ & $\begin{array}{l}\text { www.nitrc.org/projects/spm or } \\
\text { www.fil.ion.ucl.ac.uk/spm/ }\end{array}$ & $\begin{array}{l}\text { Power et al. (2011; } \\
\text { Liao et al., 2010) }\end{array}$ \\
\hline AFNI & $\begin{array}{l}\text { AFNI is a technique for mapping } \\
\text { human brain activity. }\end{array}$ & $\begin{array}{l}\text { Analysing, processing and } \\
\text { displaying functional MRI data }\end{array}$ & www.afni.nimh.nih.gov/afn/ & $\begin{array}{l}\text { Cole et al. }(2014 ; \\
\text { Zhang et al., 2003) }\end{array}$ \\
\hline FSL & $\begin{array}{l}\text { FSL is a comprehensive library of } \\
\text { analysis tools for FMRI, MRI and } \\
\text { DTI brain imaging data. }\end{array}$ & $\begin{array}{l}\text { Diffusion application, } \\
\text { functional application, } \\
\text { structural application }\end{array}$ & www.fsl.fmrib.ox.ac.uk/fsl/ & $\begin{array}{l}\text { Iturria-Medina et al. } \\
\text { (2008;Alexander- } \\
\text { Bloch } \text { et al., 2012) }\end{array}$ \\
\hline GIFT & $\begin{array}{l}\text { GIFT can implement multiple } \\
\text { algorithms for independent component } \\
\text { analysis and blind source separation } \\
\text { of group fMRI data. }\end{array}$ & $\begin{array}{l}\text { Independent module } \\
\text { analysis }\end{array}$ & $\begin{array}{l}\text { www.mialab.mrn.org/software } \\
\text { gift/index.htm }\end{array}$ & $\begin{array}{l}\text { Vakhtin et al. (2013; } \\
\text { Stevens et al., 2009) }\end{array}$ \\
\hline REST & $\begin{array}{l}\text { REST is a convenient toolkit to } \\
\text { calculate Functional Connectivity, } \\
\text { Regional Homogeneity, Amplitude of } \\
\text { Low-Frequency Fluctuation Fractional } \\
\text { ALFF, Granger causality, degree } \\
\text { centrality, voxel mirrored homo-topic } \\
\text { connectivity and perform statistical } \\
\text { analysis. }\end{array}$ & $\begin{array}{l}\text { Data Processing of Resting- } \\
\text { State fMRI }\end{array}$ & www.restfmri.net/forum/index.php & $\begin{array}{l}\text { van Den Heuvel and } \\
\text { Pol (2010) }\end{array}$ \\
\hline CONN & $\begin{array}{l}\text { CONN is a Matlab-based cross } \\
\text {-platform software for the computation, } \\
\text { display and analysis of functional } \\
\text { connectivity in fMRI (fcMRI). }\end{array}$ & $\begin{array}{l}\text { Connectivity analysis, } \\
\text { modelling, multivariate, } \\
\text { principal component analysis, } \\
\text { regression, correlation, } \\
\text { visualization }\end{array}$ & www.conn-toolbox.org & $\begin{array}{l}\text { van Den Heuvel and } \\
\text { Pol (2010) }\end{array}$ \\
\hline $\begin{array}{l}\text { Brain } \\
\text { voyager }\end{array}$ & $\begin{array}{l}\text { Brain Voyager is a tool for the } \\
\text { advanced analysis and visualization } \\
\text { of structural and functional MRI data } \\
\text { and for combined EEG/MEG } \\
\text { distributed source imaging. }\end{array}$ & Visualization & www.brainvoyager.com & Watson et al. (2009) \\
\hline FLASCO & $\begin{array}{l}\text { FIASCO is a collection of software } \\
\text { designed to analyse fMRI data } \\
\text { using a series of processing steps. }\end{array}$ & Statistical analysis & www.stat.cmu.edu/ fiasco/ & Lazar et al. (2001) \\
\hline $\begin{array}{l}\text { Brain Net } \\
\text { Viewer }\end{array}$ & $\begin{array}{l}\text { BrainNet Viewer is a brain network } \\
\text { visualization tool, which can help } \\
\text { researchers to visualize structural } \\
\text { and functional connectivity patterns } \\
\text { from different levels in a quick, easy } \\
\text { and flexible way. }\end{array}$ & Visualization & www.nitrc.org/projectsbnv/ & Xia et al. (2013) \\
\hline NODDI & $\begin{array}{l}\text { NODDI is a new diffusion MRI } \\
\text { technique for imaging brain tissue } \\
\text { microstructure. }\end{array}$ & $\begin{array}{l}\text { Atlas application, } \\
\text { diffusion application }\end{array}$ & $\begin{array}{l}\text { www.nitrc.org/projects/noddi } \\
\text { _toolbox }\end{array}$ & $\begin{array}{l}\text { Inglese et al. }(2005 \text {; } \\
\text { Lemkaddem } \text { et al., } \\
\text { 2014) }\end{array}$ \\
\hline MRIcron & $\begin{array}{l}\text { MRIcron is a cross- platform NIfTI } \\
\text { format image viewer. It can load } \\
\text { multiple layers of images, generate } \\
\text { volume renderings and draw volumes } \\
\text { of interest. }\end{array}$ & $\begin{array}{l}\text { Volume rendering, centre } \\
\text { of mass regression, clipping, } \\
\text { two dimensional display }\end{array}$ & www.nitrc.org/projects/mricron & $\begin{array}{l}\text { Molenberghs et al. } \\
\text { (2012; Figee } \text { et al., } \\
\text { 2013) }\end{array}$ \\
\hline REX & $\begin{array}{l}\text { REX is a stand-alone toolkit for the } \\
\text { rapid and flexible exploration of ROI } \\
\text { response waveforms and other signals } \\
\text { from across large fMRI datasets. }\end{array}$ & $\begin{array}{l}\text { Time domain analysis, } \\
\text { visualization, workflow }\end{array}$ & www.nitrc.org/projects/rex/ & $\begin{array}{l}\text { Hosseini et al. } \\
\text { (2012) }\end{array}$ \\
\hline
\end{tabular}

\section{Quality Evaluation of Complex Brain Networks}

In this study, we have examined structural and functional connectivity in the human brain using features from graph theory. Because Structural and Functional Connectivity ( $\mathrm{SC}$ and $\mathrm{FC}$ ) have received great attraction over the last decade, as they offer unique insight into the coordination of brain functioning. To demonstrate the evaluations of complex brain network, we presents structural and functional graph theory analyses in two separate studies.

\section{Objectives Evaluations}

Mijalkov et al. (2017) measured the differences in global and nodal network topology in healthy controls, patients with amnestic MCI and patients with Alzheimer's disease. They carried out a graph theory 
analysis on the resting-state fMRI data of healthy controls and PD patients with MCI from the Parkinson's Progression Markers Initiative. They evaluated resting-state functional images that were acquired using an echo planar imaging sequence (repetition time $=2400 \mathrm{~ms}$; echo time $=25 \mathrm{~ms}$; flip angle $=80^{\circ} ;$ matrix $=68 \times 68$; voxel size $=$ $3.25 \times 3.25 \times 3.25 \mathrm{~mm}^{3}$ ). Bassett and Sporns (2007), illustrated that graph theory has proven to be an extremely productive framework in which to understand the structure and function of large-scale brain network and their implications for human cognition (Bassett and Sporns, 2007); alternative approaches that build on this framework-such as network control theory-necessarily require sceptical evaluation to clearly delineate value added. Now we just focus different equations on this table to measure connectivity of complex brain networks (Table 6).

Graph theory have provided a toolbox of diagnostics to describe the organization of graphs or networks. Gu et al. (2015) evaluated that using graph theory, they can identify regions of high (low) degree, while using network control theory. Moreover, they can understand the functional role of these regions as being critical for guiding the movement of the brain into many easy-to-reach (difficult-to-reach) states.

Table 6: Complex brain network measure: Equations and definitions

\begin{tabular}{|c|c|c|c|}
\hline Measures & Ref. & Equations & Definitions \\
\hline Degree of node & Liu et al. (2008) & $k_{i}=\sum_{i \in G} a(i, j)$ & $\begin{array}{l}G \text { denotes the complete set of network and } \\
a(i, j) \text { represents the element of adjacency } \\
\text { matrix. when } a(i, j)=1 \text {, there is a link } \\
\text { between nodes } i \text { and } j \text {. otherwise, } a(i, j)=0 \text {. }\end{array}$ \\
\hline Degree distribution & Caldarelli (2007) & $P(k)=\frac{n_{k}}{N}$ & $\begin{array}{l}n_{k} \text { represents the whole number of } \\
\text { nodes with degree } k \text { and } N \text { denotes the } \\
\text { whole number of nodes. }\end{array}$ \\
\hline \multirow[t]{3}{*}{ Transivity } & Honey et al. (2009) & $T(G)=\frac{\sum_{i \in G} 2 a(i, j) a(i, h) a(j, h)}{\sum_{i \in G} k_{i}\left(k_{i}-1\right)}$ & This metrics is represent only to a full \\
\hline & & & network. \\
\hline & & $C(G)$ & \\
\hline \multirow[t]{3}{*}{ Cluster coefficient } & Honey et al. (2009) & $\begin{array}{l}=\frac{1}{N} \sum_{i \in V} C(i) \\
=\frac{1}{N} \sum_{(i, j, h) \in G} \frac{2 a(i, j) a(i, h) a(j, h)}{K_{i}\left(k_{i}-1\right)}\end{array}$ & $C(i)$ denotes the cluster quantity of nodes \\
\hline & & & i. $C(i)=0$ when $k_{i}<3$ \\
\hline & & $E_{\text {lobal }}(i)$ & \\
\hline Local efficiency & Iannetti and Wise (2007) & $=\frac{1}{N_{G_{i}}\left(N_{G_{i}}-1\right)} \sum_{j, k \in G_{i}} \frac{1}{d(j, k)}$ & $G_{i}$ represent the set of neighbors of $i$. \\
\hline \multirow[t]{2}{*}{ Global efficiency } & Iannetti and Wise (2007) & $\begin{array}{l}E_{\text {global }}(G) \\
=\frac{1}{N(N-1)} \sum_{i \neq j \in G} \frac{1}{d(i, j)}\end{array}$ & $E_{\text {global }}$ evaluates in the full network. \\
\hline & & & Where $N$ denotes the total number of nodes. \\
\hline Cost or probability & Iannetti and Wise & $P_{\text {cost }}(G)=\frac{1}{N(N-1)} \sum_{i \in G} k_{i}$ & This metrics is evaluated in the full \\
\hline of connection & $(2007)$ & & $\begin{array}{l}\text { network. Where } G \text { represents the } \\
\text { network. }\end{array}$ \\
\hline Shortest path & Latora and Marchiori & $L=\frac{1}{N(N-1)} \sum_{i, j \in G, i \neq j} d(i, j)$ & $d(i, j)$ represent the shortest path length \\
\hline length & $(2001)$ & & between $i$ and $j$. \\
\hline \multirow[t]{3}{*}{ Small-worldness } & Fallani et al. (2014; & $\sigma=\frac{C / C_{\text {rand }}}{L / L_{\text {rand }}}$ & $C_{\text {rand }}$ and $L_{\text {rand }}$ are cluster coefficient \\
\hline & Humphries and & & and shortest path length evaluated to \\
\hline & Gurney, 2008) & & $\begin{array}{l}\text { randomly network from original network. } \\
\text { The network is small-world if } \sigma \gg 1\end{array}$ \\
\hline
\end{tabular}


The development of graph-theory based complex network analysis provides an important mathematical framework to characterize the global and regional topology in brain connectivity networks (Ribeiro de Paula et al., 2017). Using graph-theory based complex network analysis and network based statistic approach, Xu et al. (2016) examined the topology and connectivity in resting-state functional brain networks of adults with BPD versus healthy controls. As hypothesized, patients with BPD provided evidence for abnormalities both in topological structure and in connectivity in the intrinsic functional brain networks.

These abnormalities appear to be related to specific symptoms of BPD and can be used as features to distinguish patients with BPD from healthy controls using a machine learning classifier. These findings add to prior neuroimaging studies that have reported abnormal connections between specific brain regions in BPD and may provide new, clinically-relevant knowledge about the neurophysiology of the disease. Their graph analysis identified significant changes of small-world properties and network efficiency in patients with BPD versus healthy controls at the $0.03-0.06 \mathrm{~Hz}$ frequency band, including increased size of Largest
Connected network Component (LCC), clusteringcoefficient, small-worldness and local efficiency (Table 7).

Recently, Gong et al. (2008; Hagmann et al., 2008), maps of about 80 cortical and subcortical gray matter regions were constructed from DWI data and analysed with fMRI data using graph theory. They also found the same result. But Eguiluz et al. (2005) found controversial result although no statistical test was used. To our knowledge, only one study investigated the graph properties in both structural and functional connectivity. More recently, Messé et al. (2012) have investigated with the total of 132 nodes, distributed over the whole cortical $(n=92)$ and subcortical $(n=24)$ gray matter and the cerebellum $(n=16)$ were defined by all functional networks identified (Fig. 8).

In order to investigate similarities between structural and functional aspects of the full-brain network across subjects, the structural and functional connectivity indices were uniformly thresholded to obtain binary graphs of varying density or cost. They performed an analysis of variance and found the approximately same results (Fig. 9) of the node degrees for Structural and functional connectivity of brain network.

Table 7: Number of nodes and edges and the corrected p-value of the connected subnetwork in $0.03-0.06 \mathrm{~Hz}$ that show lower connectivity in BPD patients, under different primary threshold in NBS test

\begin{tabular}{llll}
\hline Primary threshold & No. of nodes & No. of links & Corrected $\mathrm{p}$-value \\
$\mathrm{t}=1.75, \mathrm{p} \approx 0.05$ & No significant result & & \\
$\mathrm{t}=2.05, \mathrm{p} \approx 0.025$ & 68 & 205 & 0.048 \\
$\mathrm{t}=2.5, \mathrm{p} \approx 0.01$ & 49 & 87 & 0.0408 \\
$\mathrm{t}=2.75, \mathrm{p} \approx 0.005$ & 40 & 57 & 0.0298 \\
$\mathrm{t}=3.05, \mathrm{p} \approx 0.0025$ & 26 & 26 & 0.0304 \\
$\mathrm{t}=3.4, \mathrm{p} \approx 0.001$ & No significant result & & \\
\hline
\end{tabular}
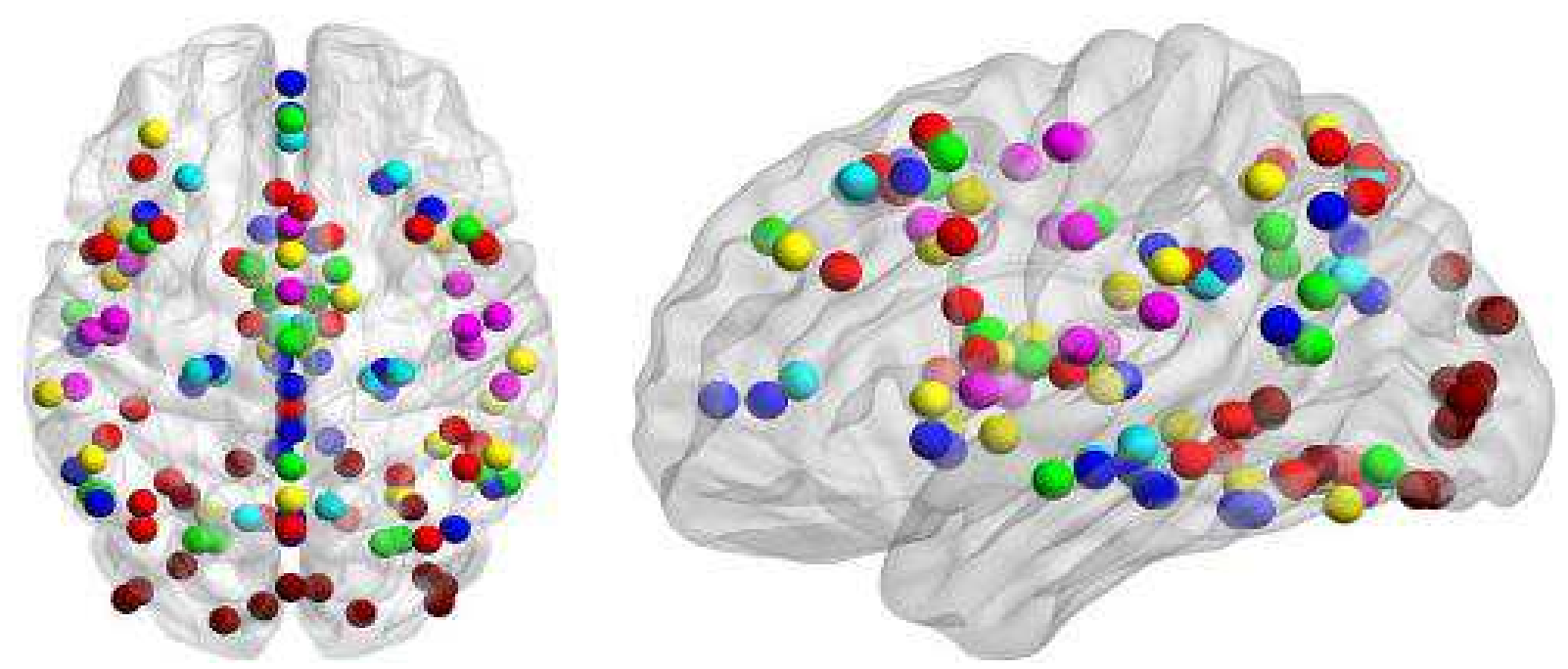

Fig. 8: Regions of interest location in axial (left) and sagittal (right) views superimposed on a brain template surface. Image courtesy of Messé et al. (2012) 

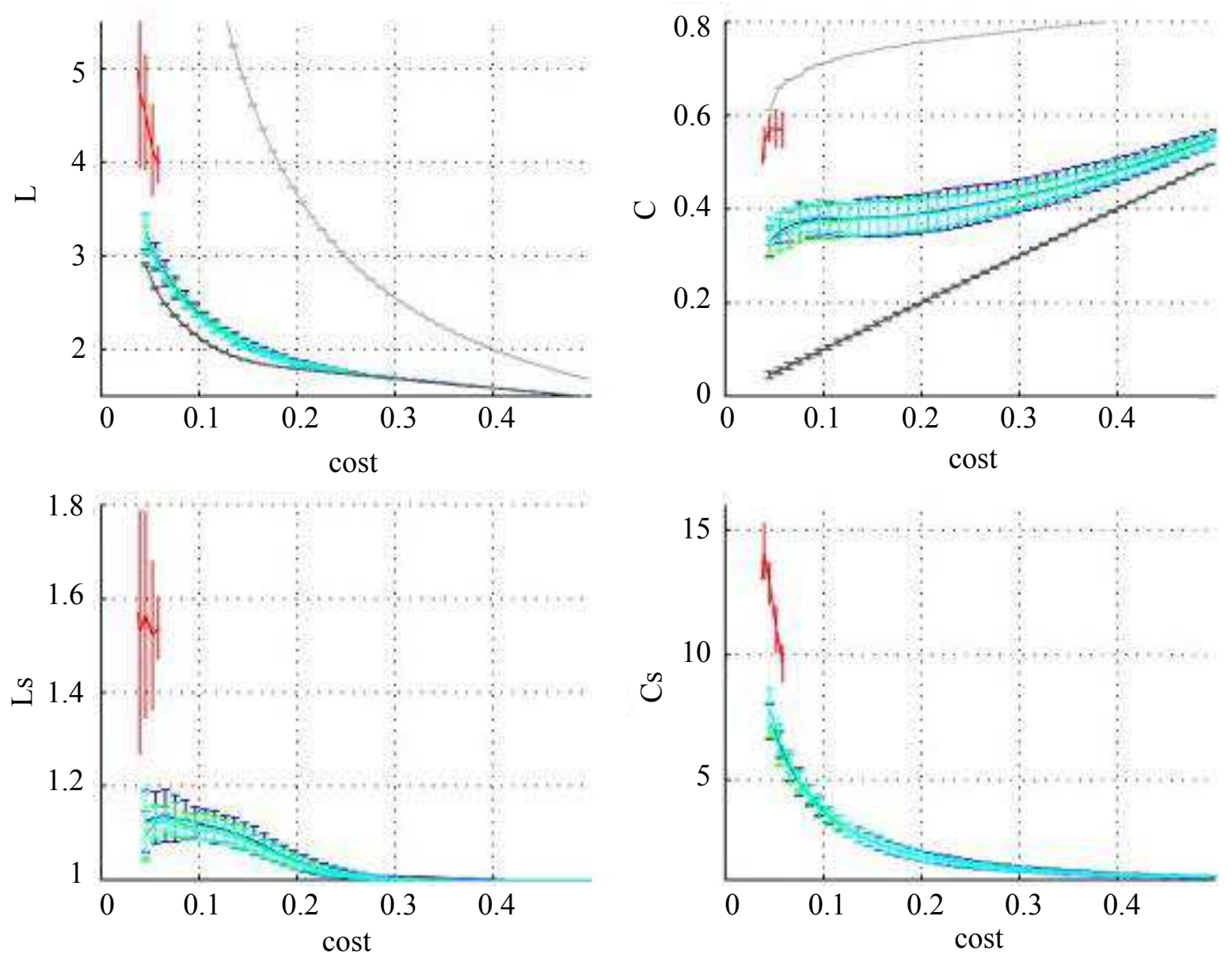

Fig. 9: Mean and standard deviation across subjects of the characteristic path length $L$ (top left), scaled characteristic path length $L_{s}$ (bottom left), clustering coefficient $C$ (top right) and scaled clustering coefficient $C_{s}$ (bottom right) as a function of the cost value for structural connectivity (red), functional connectivity at rest (dark blue), functional connectivity during the motor task (green) and functional connectivity for the visual stimulation (light blue) and the corresponding values for typical networks: Random (light grey) and lattice (dark grey), with the same size and density as those of the networks analysed. Image courtesy of Messé et al. (2012)

\section{Subjectives Evaluations}

Both structure and function can be indirectly imaged in vivo using magnetic resonance imaging (MRI). Structural connectivity using DiffusionWeighted Imaging (DWI) (Mori and Zhang, 2006) and functional connectivity using functional Magnetic Resonance Imaging (fMRI) (Logothetis et al., 2001). DWI provides information about white matter organization, allowing the reconstruction of fibre bundles (Hagmann et al., 2007; Iturria-Medina et al., 2007) and fMRI uses Blood-Oxygenation LevelDependent (BOLD) contrast to indirectly map neuronal activation (Raichle and Mintun, 2006). Various approaches have been used to investigate the nodes and edges, relaying either on structural or functional information. Strogatz (2001; Watts and Strogatz, 1998; Reijneveld et al., 2007) were applied graph theory to characterize quantitatively the structural and functional features of the complex brain network. Previous studies, in references, have shown that functional imaging (Achard et al., 2006; Salvador et al., 2005) and structural imaging (Gong et al., 2008; Hagmann et al., 2008 ) with as common results the small word properties of the analysed complex brain networks.

\section{Future Research Directions}

In the field of neuroscience, Graph-theory analysis of brain network is one of the complex task. Although many researchers already engaged with this research field still there are some challenging issues need to be identified. Complex brain network analysis b used on the graph could be both useful and feasible for more profound studies but still required for more systematic assessment. Besides, in complex brain networks, there are deficiencies of a gold standard for the meaning and descriptions of network nodes and edges or links. 
Ensuring the suitable use of network analysis, researchers still have to need to take attention when choosing the right network demonstration of the brain connectivity. The most prominent area of expansion is, structural brain connectivity had modelled for structural associations among different neuronal elements derived from resting fMRI and functional brain connectivity had modelled for the functional associations among brain regions measured with diffusion MRI but nobody tried for the whole-brain network. So, the combination of both structural and functional connectivity can be modelled as networks with different neuroimaging modalities. Because the combination of different imaging modalities to determine the relationship of the structural and functional connectivity of the brain. We hope this multimodal imaging techniques of the future will provide integrative evidence to map the patterns of whole brain connectivity.

\section{Conclusion}

Graph based analysis of Complex brain network has emerged as an important technique to visualise functional and structural brain connectivity. We characterized two prominent procedures that measure local and global properties of complex brain networks. The associated brain connectivity prominent technique allows researchers to begin exploring network features of complex functional and structural imaging datasets. We also show some challenging issues that will be playing an increasingly important role in the evolvement of brain's network in near future.

\section{Acknowledgement}

We would like to thank the anonymous reviewers and editor for their constructive comments and suggestions on earlier version of this paper. The work described in this paper has been partly supported by the ARC DP Project: DP140100841 and Victoria University, Australia.

\section{Author's Contributions}

All authors equally contributed in this work.

\section{Ethics}

This review article is original and have never been published anywhere. The corresponding author confirms that all of the authors have read and approved the manuscript and no ethical issues involved.

\section{Referencess}

Achard, S. and E. Bullmore, 2007. Efficiency and cost of economical brain functional networks. PLoS Comput. Biol., 3: 268-276. DOI: 10.1371/journal.pcbi.0030017
Achard, S., R. Salvador, B. Whitcher, J. Suckling and E. Bullmore, 2006. A resilient, low-frequency, smallworld human brain functional network with highly connected association cortical hubs. J. Neurosci., 26: 63-72. DOI: 10.1523/JNEUROSCI.3874-05.2006

Ahsan, H., M. Akbar and A.U.A. Bhatti, 2009. Application and advantage of functional magnetic resonance imaging and Blood Oxygen Level Dependant (BOLD) imaging modality. J. Pak. Med. Assoc., 59: 794-794.

Alexander-Bloch, A.F., P.E. Vértes, R. Stidd, F. Lalonde and L. Clasen et al., 2012. The anatomical distance of functional connections predicts brain network topology in health and schizophrenia. Cerebral Cortex, 23: 127-138. DOI: 10.1093/cercor/bhr388

Arfanakis, K., B.P. Hermann, B.P. Rogers, J.D. Carew and M. Seidenberg et al., 2002. Diffusion tensor MRI in temporal lobe epilepsy. Magnet. Resonance Imag., 20: 511-519.

DOI: $10.1016 / \mathrm{S} 0730-725 \mathrm{X}(02) 00509-\mathrm{X}$

Bammer, R., 2003. Basic principles of diffusionweighted imaging. Eur. J. Radiol., 45: 169-184. DOI: $10.1016 / \mathrm{S} 0720-048 \mathrm{X}(02) 00303-0$

Bassett, D.S. and O. Sporns, 2007. Network neuroscience. Nature Neurosci., 20: 353-364. DOI: 10.1038/nn.4502

Boccaletti, S., V. Latora, Y. Moreno, M. Chavez and D.U. Hwang, 2006. Complex networks: Structure and dynamics. Phys. Rep., 424: 175-308.

DOI: $10.1016 /$ j.physrep.2005.10.009

Boersma, M., D.J. Smit, H. de Bie, G.C.M. Van Baal and D.I. Boomsma et al., 2011. Network analysis of resting state EEG in the developing young brain: Structure comes with maturation. Human Brain Mapp., 32: 413-425. DOI: 10.1002/hbm.21030

Booth, B.G. and G. Hamarneh, 2010. Brain connectivity mapping and analysis using diffusion MRI.

Brown, J.A., K.H. Terashima, A.C. Burggren, L.M. Ercoli and K.J. Miller et al., 2011. Brain network local interconnectivity loss in aging APOE-4 allele carriers. Proc. Nat. Acad. Sci., 108: 20760-20765. DOI: $10.1073 /$ pnas. 1109038108

Buckner, R.L., J. Sepulcre, T. Talukdar, F.M. Krienen and H. Liu et al., 2009. Cortical hubs revealed by intrinsic functional connectivity: Mapping, assessment of stability and relation to Alzheimer's disease. J. Neurosci., 29: 1860-1873. DOI: 10.1523/JNEUROSCI.5062-08.2009

Bullmore, E. and O. Sporns, 2009. Complex brain networks: Graph theoretical analysis of structural and functional systems. Nature Rev. Neurosci., 10: 186-198. DOI: $10.1038 / \mathrm{nrn} 2575$

Bullmore, E. and O. Sporns, 2012. The economy of brain network organization. Nature Rev. Neurosci., 13: 336-349. DOI: 10.1038/nrn3214 
Calabrese, E., A. Badea, G. Cofer, Y. Qi and G.A. Johnson, 2015. A diffusion MRI tractography connectome of the mouse brain and comparison with neuronal tracer data. Cerebral Cortex, 25: 4628-4637. DOI: $10.1093 /$ cercor/bhv121

Caldarelli, G., 2007. Scale-Free Networks: Complex Webs in Nature and Technology. 1st Edn., Oxford University Press, ISBN-10: 0199211515, pp: 336.

Chang, T.Y., K.L. Huang, M.Y. Ho, P.S. Ho and C.H. Chang et al., 2016. Graph theoretical analysis of functional networks and its relationship to cognitive decline in patients with carotid stenosis. J. Cerebral Blood Flow Metabolism, 36: 808-818. DOI: $10.1177 / 0271678 X 15608390$

Chen, J.E. and G.H. Glover, 2015. Functional magnetic resonance imaging methods. Neuropsychol. Rev., 25: 289-313. DOI: $10.1007 / \mathrm{s} 11065-015-9294-9$

Chenevert, T.L., L.D. Stegman, J.M. Taylor, P.L. Robertson and H.S. Greenberg et al., 2000. Diffusion magnetic resonance imaging: An early surrogate marker of therapeutic efficacy in brain tumors. J. Nat. Cancer Inst., 92: 2029-2036.

DOI: 10.1093/jnci/92.24.2029

Ciric, R., J. Nomi, L. Uddin and A. Satpute, 2016. Contextual connectivity: A framework for understanding the intrinsic dynamic architecture of large-scale functional brain networks.

Clark, C. and T. Byrnes, 2008. DTI and Tractography in Neurosurgical Planning. 1st Edn., Oxford University Press, ISBN-10: 9780195369779.

Cole, M.W., D.S. Bassett, J.D. Power, T.S. Braver and S.E. Petersen, 2014. Intrinsic and task-evoked network architectures of the human brain. Neuron, 83: 238-251. DOI: 10.1016/j.neuron.2014.05.014

Colombo, B., M.A. Rocca, R. Messina, S. Guerrieri and M. Filippi, 2015. Resting-state fMRI functional connectivity: A new perspective to evaluate pain modulation in migraine? Neurol. Sci., 36: 41-45. DOI: $10.1007 / \mathrm{s} 10072-015-2145-\mathrm{X}$

Daimiwal, N., M. Sundhararajan and R. Shriram, 2012. Applications of fMRI for brain mapping.

de Haan, W., Y.A. Pijnenburg, R.L. Strijers, Y. van der Made and W.M. van der Flier et al., 2009. Functional neural network analysis in frontotemporal dementia and Alzheimer's disease using EEG and graph theory. BMC Neurosci., 10; 1-12.

DOI: $10.1186 / 1471-2202-10-101$

Debaere, F., S.P. Swinnen, E. Béatse, S. Sunaert and P. Van Hecke et al., 2001. Brain areas involved in interlimb coordination: A distributed network. Neuroimage, 14: 947-958.

DOI: $10.1006 /$ nimg.2001.0892
Del Etoile, J. and H. Adeli, 2017. Graph theory and brain connectivity in alzheimer's disease. Neuroscientist.

Delouche, A., A. Attyé, O. Heck, S. Grand and A. Kastler et al., 2016. Diffusion MRI: Pitfalls, literature review and future directions of research in mild traumatic brain injury. Eur. J. Radiol., 85: 25-30. DOI: 10.1016/j.ejrad.2015.11.004

Dennis, E.L. and P.M. Thompson, 2014. Functional brain connectivity using fMRI in aging and Alzheimer's disease. Neuropsychol. Rev., 24: 49-62. DOI: $10.1007 / \mathrm{s} 11065-014-9249-6$

Eguiluz, V.M., D.R. Chialvo, G.A. Cecchi, M. Baliki and A.V. Apkarian, 2005. Scale-free brain functional networks. Phys. Rev. Lett., 94: 1-4. DOI: 10.1103/PhysRevLett.94.018102

Engel Jr, J., P.M. Thompson, J.M. Stern, R.J. Staba and A. Bragin et al., 2013. Connectomics and epilepsy. Curr. Opin. Neurol., 26: 186-194. DOI: 10.1097/WCO.0b013e32835ee5b8

Fair, D.A., A.L. Cohen, J.D. Power, N.U. Dosenbach and J.A. Church et al., 2009. Functional brain networks develop from a "local to distributed" organization. PLoS Comput. Biol.

Fallani, F.D.V., J. Richiardi, M. Chavez and S. Achard, 2014. Graph analysis of functional brain networks: Practical issues in translational neuroscience. Phil. Trans. R. Soc. B, 369: 1-17.

DOI: $10.1098 /$ rstb.2013.0521

Figee, M., J. Luigjes, R. Smolders, C.E. Valencia-Alfonso and G. Van Wingen et al., 2013. Deep brain stimulation restores frontostriatal network activity in obsessive-compulsive disorder. Nature Neurosci., 16: 386-387. DOI: 10.1038/nn.3344

Fox, M.D. and M.E. Raichle, 2007. Spontaneous fluctuations in brain activity observed with functional magnetic resonance imaging. Nature Rev. Neurosci., 8: 700-711. DOI: 10.1038/nrn2201

Friston, K., C. Frith, P. Liddle and R. Frackowiak, 1993. Functional connectivity: the principal-component analysis of large (PET) data sets. J. Cerebral Blood Flow Metabolism, 13: 5-14. DOI: $10.1038 /$ jcbfm.1993.4

Gallichan, D., 2017. Diffusion MRI of the human brain at Ultra-High Field (UHF): A review. NeuroImage.

Gao, L.1. and T. Wu, 2016. The study of brain functional connectivity in Parkinson's disease. Translat. Neurodegenerat., 5: 1-7. DOI: $10.1186 / \mathrm{s} 40035-016-0066-0$

Glahn, D.C., A. Winkler, P. Kochunov, L. Almasy and R. Duggirala et al., 2010. Genetic control over the resting brain. Proc. Nat. Acad. Sci., 107: 1223-1228. DOI: 10.1073/pnas.0909969107

Goelman, G., R. Dan, F. Růžička, O. Bezdicek and E. Růžička et al., 2017. Frequency-phase analysis of resting-state functional MRI. Sci. Rep., 7: 1-12. 
Gong, G., Y. He, L. Concha, C. Lebel and D.W. Gross et al., 2008. Mapping anatomical connectivity patterns of human cerebral cortex using in vivo diffusion tensor imaging tractography. Cerebral Cortex, 19: 524-536. DOI: $10.1093 /$ cercor/bhn102

Gore, J.C., 2003. Principles and practice of functional MRI of the human brain. J. Clin. Investigat., 112: 1-6. DOI: 10.1172/JCI19010

Govindan, R.M. and H.T. Chugani, 2010. Diffusion MRI in Epilepsy. In: Neuroimaging in Epilepsy, Chugani, H.T. (Ed.), OUP USA, ISBN-10: 0195342763, pp: 92-105.

Grady, L.J. and J.R. Polimeni, 2010. Introduction to Discrete Calculus. In: Discrete Calculus, Hamrick, B. (Ed.) Springer, London, ISBN-10: 978-1-84996-290-2, pp: 13-89.

Gu, S., F. Pasqualetti, M. Cieslak, Q.K. Telesford and B.Y. Alfred et al., 2015. Controllability of structural brain networks. Nature Commun., 6: 1-10.

Guye, M., G. Bettus, F. Bartolomei and P.J. Cozzone, 2010. Graph theoretical analysis of structural and functional connectivity MRI in normal and pathological brain networks. Magnet. Resonance Mater. Phy. Biol. Med., 23: 409-421.

DOI: $10.1007 / \mathrm{s} 10334-010-0205-\mathrm{z}$

Hachinski, V., C. Iadecola, R.C. Petersen, M.M. Breteler and D.L. Nyenhuis et al., 2006. National Institute of Neurological Disorders and Stroke-Canadian stroke network vascular cognitive impairment harmonization standards. Stroke, 37: 2220-2241. DOI: $10.1161 / 01 . S T R .0000237236 .88823 .47$

Hagmann, P., L. Cammoun, X. Gigandet, R. Meuli and C.J. Honey et al., 2008. Mapping the structural core of human cerebral cortex. PLoS Biol., 6: 1479-1493. DOI: 10.1371/journal.pbio.0060159

Hagmann, P., M. Kurant, X. Gigandet, P. Thiran and V.J. Wedeen et al., 2007. Mapping human wholebrain structural networks with diffusion MRI. PloS One, 2: 1-10. DOI: 10.1371/journal.pone.0000597.

Hart, M.G., R.J. Ypma, R. Romero-Garcia, S.J. Price and J. Suckling, 2016. Graph theory analysis of complex brain networks: New concepts in brain mapping applied to neurosurgery. J. Neurosurgery, 124; 1665-678. DOI: 10.3171/2015.4.JNS142683

Hassan, M., I. Merlet, A. Mheich, A. Kabbara and A. Biraben et al., 2017a. Identification of interictal epileptic networks from dense-EEG. Brain Topography, 30: 60-76.

DOI: $10.1007 / \mathrm{s} 10548-016-0517-\mathrm{z}$

Hassan, M., L. Chaton, P. Benquet, A. Delval and C. Leroy et al., 2017b. Functional connectivity disruptions correlate with cognitive phenotypes in Parkinson's disease. NeuroImage: Clin., 14: 591-601. DOI: 10.1016/j.nicl.2017.03.002
Hata, M., H. Kazui, T. Tanaka, R. Ishii and L. Canuet et al., 2016. Functional connectivity assessed by resting state EEG correlates with cognitive decline of Alzheimer's disease-An eLORETA study. Clin. Neurophysiol., 127: 1269-1278.

DOI: 10.1016/j.clinph.2015.10.030

He, Y. and A. Evans, 2010. Graph theoretical modeling of brain connectivity. Curr. Opin. Neurol., 23: 341-350. DOI: 10.1097/WCO.0b013e32833aa567

Hennig, J., O. Speck, M.A. Koch and C. Weiller, 2003. Functional magnetic resonance imaging: A review of methodological aspects and clinical applications. J. Magnet. Resonance Imag., 18: 1-15. DOI: $10.1002 /$ jmri.10330

Holodny, A.I. and M. Ollenschlager, 2002. Diffusion imaging in brain tumors. Neuroimag. Clin. North Am., 12: 107-124. DOI: $10.1016 / \mathrm{S} 1052-5149(03) 00072-8$

Honey, C., O. Sporns, L. Cammoun, X. Gigandet and J.P. Thiran et al., 2009. Predicting human restingstate functional connectivity from structural connectivity. Proc. Nat. Acad. Sci., 106: 2035-2040. DOI: $10.1073 /$ pnas.0811168106

Hosseini, S.H., F. Hoeft and S.R. Kesler, 2012. GAT: A graph-theoretical analysis toolbox for analyzing between-group differences in large-scale structural and functional brain networks. PloS One, 7: 1-15. DOI: 10.1371/journal.pone.0040709

Humphries, M.D. and K. Gurney, 2008. Network 'smallworld-ness': A quantitative method for determining canonical network equivalence. PloS One, 3: 1-10. DOI: 10.1371/journal.pone.0002051

Hüppi, P.S. and J. Dubois, 2006. Diffusion Tensor Imaging Of Brain Development. In: Seminars in Fetal and Neonatal Medicine, Donn, S.M. (Ed.), Elsevier, pp: 489-497.

Iannetti, G. and R.G. Wise, 2007. BOLD functional MRI in disease and pharmacological studies: Room for improvement? Magnet. Resonance Imag., 25: 978-988. DOI: 10.1016/j.mri.2007.03.018

Inglese, M., S. Makani, G. Johnson, B.A. Cohen and J.A. Silver et al., 2005. Diffuse axonal injury in mild traumatic brain injury: A diffusion tensor imaging study. J. Neurosurgery, 103: 298-303. DOI: 10.3171/jns.2005.103.2.0298

Iturria-Medina, Y., E. Canales-Rodriguez, L. Melie-Garcia, P. Valdes-Hernandez and E. Martinez-Montes et al., 2007. Characterizing brain anatomical connections using diffusion weighted MRI and graph theory. Neuroimage, 36: 645-660.

DOI: 10.1016/j.neuroimage.2007.02.012

Iturria-Medina, Y., R.C. Sotero, E.J. Canales-Rodríguez, Y. Alemán-Gómez and L. Melie-García, 2008. Studying the human brain anatomical network via diffusion-weighted MRI and graph theory. Neuroimage, 40: 1064-1076.

DOI: 10.1016/j.neuroimage.2007.10.060 
Johansen-Berg, H. and T.E. Behrens, 2013. Diffusion MRI: From Quantitative Measurement to In vivo Neuroanatomy. 2nd Edn., Academic Press, ISBN10: 9780124055094 , pp: 632.

Jones, D.K., 2010. Challenges and limitations of quantifying brain connectivity in vivo with diffusion MRI. Imag. Med., 2: 341- 355.

DOI: $10.2217 /$ iim. 10.21

Joo, S.H., H.K. Lim and C.U. Lee, 2016. Three largescale functional brain networks from resting-state functional MRI in subjects with different levels of cognitive impairment. Psychiatry Investigat., 13: 1-7. DOI: $10.4306 /$ pi.2016.13.1.1

Kabbara, A., W.E. Falou, M. Khalil, F. Wendling and M. Hassan, 2016a. Graph analysis of spontaneous brain network using EEG source connectivity.

Kabbara, A., M. Khalil, W. El-Falou, H. Eid and M. Hassan, 2016b. Functional brain connectivity as a new feature for P300 speller. PloS One, 11: 1-18. DOI: 10.1371/journal.pone.0146282

Kahn, A.E., M.G. Mattar, J.M. Vettel, N.F. Wymbs and S.T. Grafton et al., 2017. Structural pathways supporting swift acquisition of new visuomotor skills. Cerebral Cortex, 27: 173-184.

DOI: 10.1093/cercor/bhw335

Kamalian, S., S. Kamalian, M.B. Maas, G.V. Goldmacher and S. Payabvash et al., 2011. CT cerebral blood flow maps optimally correlate with admission diffusion-weighted imaging in acute stroke but thresholds vary by postprocessing platform. Stroke, 42 : 1923-1928. DOI: 10.1161/STROKEAHA.110.610618

Latora, V. and M. Marchiori, 2001. Efficient behavior of small-world networks. Phys. Rev. Lett., 87: 1-4. DOI: 10.1103/PhysRevLett.87.198701

Lazar, N.A., W.F. Eddy, C.R. Genovese and J. Welling, 2001. Statistical issues in fMRI for brain imaging. Int. Stat. Rev., 69: 105-127. DOI: 10.2307/1403532

Le Bihan, D., C. Poupon, A. Amadon and F. Lethimonnier, 2006. Artifacts and pitfalls in diffusion MRI. J. Magnet. Resonance Imag., 24: 478-488.

DOI: $10.1002 /$ jmri.20683

Lemkaddem, A., A. Daducci, N. Kunz, F. Lazeyras and M. Seeck et al., 2014. Connectivity and tissue microstructural alterations in right and left temporal lobe epilepsy revealed by diffusion spectrum imaging. NeuroImage: Clin., 5: 349-358.

DOI: 10.1016/j.nicl.2014.07.013

Li, J., Y. Shi and A.W. Toga, 2016. Mapping brain anatomical connectivity using diffusion magnetic resonance imaging: Structural connectivity of the human brain. IEEE Signal Process. Magazine, 33: 36-51. DOI: 10.1109/MSP.2015.2510024

Li, Y., V. Jewells, M. Kim, Y. Chen and A. Moon et al., 2013. Diffusion tensor imaging based network analysis detects alterations of neuroconnectivity in patients with clinically early relapsing-remitting multiple sclerosis. Human Brain Mapp., 34: 33763391. DOI: $10.1002 / \mathrm{hbm} .22158$
Li, Y., Y. Liu, J. Li, W. Qin and K. Li et al., 2009. Brain anatomical network and intelligence. PLoS Comput. Biol., 5: 1-17. DOI: 10.1371/journal.pcbi.1000395

Liao, W., Z. Zhang, Z. Pan, D. Mantini and J. Ding et al., 2010. Altered functional connectivity and smallworld in mesial temporal lobe epilepsy. PloS One, 5: 1-11. DOI: 10.1371/journal.pone.0008525

Liu, B., M. Song, J. Li, Y. Liu and K. Li et al., 2010. Prefrontal-related functional connectivities within the default network are modulated by COMT val ${ }^{158}$ met in healthy young adults. J. Neurosci., 30: 64-69. DOI: 10.1523/JNEUROSCI.3941-09.2010

Liu, J., J. Liang, W. Qin, J. Tian and K. Yuan et al., 2009. Dysfunctional connectivity patterns in chronic heroin users: An fMRI study. Neurosci. Lett., 460: 72-77. DOI: 10.1016/j.neulet.2009.05.038

Liu, Y., M. Liang, Y. Zhou, Y. He and Y. Hao et al., 2008. Disrupted small-world networks in schizophrenia. Brain, 131: 945-961. DOI: 10.1093/brain/awn018

Logothetis, N.K., J. Pauls, M. Augath, T. Trinath and A. Oeltermann, 2001. Neurophysiological investigation of the basis of the fMRI signal. Nature, 412: 150-157. DOI: 10.1038/35084005

Maier, S.E., Y. Sun and R.V. Mulkern, 2010. Diffusion imaging of brain tumors. NMR Biomed., 23: 849-864. DOI: 10.1002/nbm.1544

Maihöfner, C., C. Forster, F. Birklein, B. Neundörfer and H.O. Handwerker, 2005. Brain processing during mechanical hyperalgesia in complex regional pain syndrome: A functional MRI study. Pain, 114: 93-103.

Matthews, P. and P. Jezzard, 2004. Functional magnetic resonance imaging. J. Neurol. Neurosurgery Psychiatry, 75: 6-12.

McColgan, P., A. Razi, S. Gregory, K.K. Seunarine and A. Durr et al., 2017. Structural and functional brain network correlates of depressive symptoms in premanifest Huntington's disease. Human Brain Mapp., 38: 2819-2829. DOI: 10.1002/hbm.23527

Messé, A., G. Marrelec, P. Bellec, V. Perlbarg and J. Doyon et al., 2012. Comparing structural and functional graph theory features in the human brain using multimodal MRI. IRBM, 33: 244-253.

DOI: $10.1016 /$ j.irbm.2012.04.005

Meunier, D., S. Achard, A. Morcom and E. Bullmore, 2009. Age-related changes in modular organization of human brain functional networks. Neuroimage, 44: 715-723. DOI: 10.1016/j.neuroimage.2008.09.062

Mijalkov, M., E. Kakaei, J.B. Pereira, E. Westman and G. Volpe, 2017. BRAPH: A graph theory software for the analysis of brain connectivity.

Molenberghs, P., R. Cunnington and J.B. Mattingley, 2012. Brain regions with mirror properties: A metaanalysis of 125 human fMRI studies. Neurosci. Biobehav. Rev., 36: 341-349. DOI: 10.1016/j.neubiorev.2011.07.004 
Mori, S. and J. Zhang, 2006. Principles of diffusion tensor imaging and its applications to basic neuroscience research. Neuron, 51: 527-539.

DOI: $10.1016 /$ j.neuron.2006.08.012

Mori, S. and P.B. Barker, 1999. Diffusion magnetic resonance imaging: Its principle and applications. Anatomical Record, 257: 102-109.

DOI:

$10.1002 /(\mathrm{SICI}) 1097-$ 0185(19990615)257:3<102::AID-AR7>3.0.CO;2-6

Mueller, B.A., K.O. Lim, L. Hemmy and J. Camchong, 2015. Diffusion MRI and its role in neuropsychology. Neuropsychol. Rev., 25: 250-271. DOI: $10.1007 / \mathrm{s} 11065-015-9291-\mathrm{z}$

Nakamura, T., F.G. Hillary and B.B. Biswal, 2009. Resting network plasticity following brain injury. PloS One, 4: 1-9. DOI: 10.1371/journal.pone.0008220

Neil, J., J. Miller, P. Mukherjee and P.S. Hüppi, 2002. Diffusion tensor imaging of normal and injured developing human brain-a technical review. NMR Biomed., 15: 543-552. DOI: 10.1002/nbm.784

Onias, H., A. Viol, F. Palhano-Fontes, K.C. Andrade and M. Sturzbecher et al., 2014. Brain complex network analysis by means of resting state fMRI and graph analysis: Will it be helpful in clinical epilepsy?. Epilepsy Behav., 38; 71-80. DOI: 10.1016/j.yebeh.2013.11.019

Power, J.D., A.L. Cohen, S.M. Nelson, G.S. Wig and K.A. Barnes et al., 2011. Functional network organization of the human brain. Neuron, 72: 665-678. DOI: 10.1016/j.neuron.2011.09.006

Provenzale, J.M., S. Mukundan and D.P. Barboriak, 2006. Diffusion-weighted and perfusion MR imaging for brain tumor characterization and assessment of treatment response. Radiology, 239: 632-649. DOI: 10.1148/radiol.2393042031

Raichle, M.E. and M.A. Mintun, 2006. Brain work and brain imaging. Annu. Rev. Neurosci., 29: 449-476. DOI: 10.1146/annurev.neuro.29.051605.112819

Reijneveld, J.C., S.C. Ponten, H.W. Berendse and C.J. Stam, 2007. The application of graph theoretical analysis to complex networks in the brain. Clin. Neurophysiol., 118: 2317-2331.

DOI: 10.1016/j.clinph.2007.08.010

Ribeiro de Paula, D., E. Ziegler, P.M. Abeyasinghe, T.K. Das and C. Cavaliere et al., 2017. A method for independent component graph analysis of resting-state fMRI. Brain Behav., 7: 1-12.

Rodic, S. and P.J. Zhao, 2015. A brief review of neuroimaging using functional Magnetic Resonance Imaging (fMRI). UWOMJ, 84: 1-10.

Rovaris, M. and M. Filippi, 2007. Diffusion tensor MRI in multiple sclerosis. J. Neuroimag., 17: 27S-30S. DOI: $10.1111 / \mathrm{j} .1552-6569.2007 .00133 . \mathrm{x}$

Rubinov, M. and O. Sporns, 2010. Complex network measures of brain connectivity: Uses and interpretations. Neuroimage, 52; 1059-1069.

DOI: $10.1016 /$ j.neuroimage.2009.10.003
Salvador, R., J. Suckling, M.R. Coleman, J.D. Pickard and D. Menon et al., 2005. Neurophysiological architecture of functional magnetic resonance images of human brain. Cerebral Cortex, 15: 1332-1342. DOI: 10.1093/cercor/bhi016

Schaefer, P.W., P.E. Grant and R.G. Gonzalez, 2000. Diffusion-weighted MR imaging of the brain. Radiology, 217: 331-345.

DOI: 10.1148/radiology.217.2.r00nv24331

Schultz, T., G. Nedjati-Gilani, A. Venkataraman, L. Donnell and E. Panagiotaki, 2016. Computational Diffusion MRI and Brain Connectivity. 1st Edn., Springer International Publishing, ISBN-10: 3319376845, pp: 255.

Song, M. and T. Jiang, 2012. A review of functional magnetic resonance imaging for Brainnetome. Neurosci. Bull., 28: 389-398.

DOI: $10.1007 / \mathrm{s} 12264-012-1244-4$

Song, M., Y. Zhou, J. Li, Y. Liu and L. Tian et al., 2008. Brain spontaneous functional connectivity and intelligence. Neuroimage, 41: 1168-1176.

Sporns, O., 2011. The human connectome: A complex network. Annals New York Acad. Sci., 1224: 109-125. DOI: 10.1111/j.1749-6632.2010.05888.x

Sporns, O., 2014. Contributions and challenges for network models in cognitive neuroscience. Nature Neurosci., 17: 652-660. DOI: 10.1038/nn.3690

Stevens, M.C., K.A. Kiehl, G.D. Pearlson and V.D. Calhoun, 2009. Brain network dynamics during error commission. Human Brain Mapp., 30: 24-37. DOI: $10.1002 / \mathrm{hbm} .20478$

Strogatz, S.H., 2001. Exploring complex networks. Nature, 410: 268-276. DOI: 10.1038/35065725

Sullivan, E. and A. Pfefferbaum, 2011. DTI in Aging and Age-Related Neurodegenerative Disorders. In: Diffusion MRI: Theory, Methods and Applications, Jones, D.K. (Ed.), Springer, New York.

Sun, J., S. Tong and G.Y. Yang, 2012. Reorganization of brain networks in aging and age-related diseases. Aging Dis., 3: 181-193.

Supekar, K., M. Musen and V. Menon, 2009. Development of large-scale functional brain networks in children. PLoS Biol., 7: 1-15.

DOI: $10.1371 /$ journal.pbio.1000157

Supekar, K., V. Menon, D. Rubin, M. Musen and M.D. Greicius, 2008. Network analysis of intrinsic functional brain connectivity in Alzheimer's disease. PLoS Comput. Biol., 4: 1-11. DOI: $10.1371 /$ journal.pcbi.1000100

Thirion, B., G. Flandin, P. Pinel, A. Roche and P. Ciuciu et al., 2006. Dealing with the shortcomings of spatial normalization: Multi-subject parcellation of fMRI datasets. Human Brain Mapp., 27: 678-693. DOI: 10.1002/hbm.20210 
Thomas, C., Q.Y. Frank, M.O. Irfanoglu, P. Modi and K.S. Saleem et al., 2014. Anatomical accuracy of brain connections derived from diffusion MRI tractography is inherently limited. Proc. Nat. Acad. Sci., 111: 16574-16579.

DOI: $10.1073 /$ pnas. 1405672111

Vakhtin, A.A., V.D. Calhoun, R.E. Jung, J.L. Prestopnik and P.A. Taylor et al., 2013. Changes in intrinsic functional brain networks following blast-induced mild traumatic brain injury. Brain Injury, 27: 1304-1310. DOI: $10.3109 / 02699052.2013 .823561$

Valencia, M., M. Pastor, M. Fernández-Seara, J. Artieda and J. Martinerie et al., 2009. Complex modular structure of large-scale brain networks. Chaos: Interdisciplinary J. Nonlinear Sci., 19: 1-8.

DOI: $10.1063 / 1.3129783$

van Den Heuvel, M.P. and H.E.H. Pol, 2010. Exploring the brain network: A review on resting-state fMRI functional connectivity.

Eur.

Neuropsychopharmacol., 20: 519-534.

DOI: 10.1016/j.euroneuro.2010.03.008

van den Heuvel, M.P., C.J. Stam, R.S. Kahn and H.E.H. Pol, 2009. Efficiency of unctional brain networks and intellectual performance. J. Neurosci., 29: 7619-7624.

van der Horn, H.J., E.J. Liemburg, M.E. Scheenen, M.E. de Koning and J.M. Spikman et al., 2017. Graph analysis of functional brain networks in patients with mild traumatic brain injury. PLoS one, 12: 1-19. DOI: 10.1371/journal.pone.0171031

Van Everdingen, K., J. Van der Grond, L. Kappelle, L. Ramos and W. Mali, 1998. Diffusion-weighted magnetic resonance imaging in acute stroke. Stroke, 29: 1783-1790. DOI: 10.1161/01.STR.29.9.1783

van Gelderen, P., M.H. de Vleeschouwer, D. DesPres, J. Pekar and P. van Zijl et al., 1994. Water diffusion and acute stroke. Magnet. Resonance Med., 31: 154-163.

DOI: $10.1002 / \mathrm{mrm} .1910310209$

van Straaten, E.C. and C.J. Stam, 2013. Structure out of chaos: functional brain network analysis with EEG, MEG and functional MRI. Eur. Neuropsychopharmacol., 23; 7-18. DOI: 10.1016/j.euroneuro.2012.10.010

Wang, J., X. Zuo and Y. He, 2010. Graph-based network analysis of resting-state functional MRI. Frontiers Syst. Neurosci., 4: 1-41.

Wang, L., C. Zhu, Y. He, Y. Zang and Q. Cao et al., 2009. Altered small-world brain functional networks in children with attention-deficit/hyperactivity disorder. Human Brain Mapp., 30: 638-649. DOI: $10.1002 / \mathrm{hbm} .20530$

Wang, X., Y. Ren and W. Zhang, 2017. Depression disorder classification of fMRI data using sparse low-rank functional brain network and graph-based features. Comput. Math. Meth. Med., 2017: 1-11. DOI: $10.1155 / 2017 / 3609821$
Warach, S., J. Gaa, B. Siewert, P. Wielopolski and R.R. Edelman, 1995. Acute human stroke studied by whole brain echo planar diffusion-weighted magnetic resonance imaging. Annals Neurol., 37: 231-241. DOI: 10.1002/ana.410370214

Wardlaw, J.M., C. Smith and M. Dichgans, 2013. Mechanisms of sporadic cerebral small vessel disease: Insights from neuroimaging. Lancet Neurol., 12: 483-497. DOI: $10.1016 / \mathrm{S} 1474-4422(13) 70060-7$

Warren, D.E., M.J. Sutterer, J. Bruss, T.J. Abel and A. Jones et al., 2017. Surgically disconnected temporal pole exhibits resting functional connectivity with remote brain regions.

Watson, A., W. El-Deredy, G.D. Iannetti, D. Lloyd and I. Tracey et al., 2009. Placebo conditioning and placebo analgesia modulate a common brain network during pain anticipation and perception. $\mathrm{PAIN} \AA, 145$ : 24-30. DOI: 10.1016/j.pain.2009.04.003

Watts, D.J. and S.H. Strogatz, 1998. Collective dynamics of 'small-world' networks. Nature, 393: 440-442. DOI: $10.1038 / 30918$

White, T., M. Nelson and K.O. Lim, 2008. Diffusion tensor imaging in psychiatric disorders. Top. Magnet. Resonance Imag., 19: 97-109.

Xia, M., J. Wang and Y. He, 2013. BrainNet viewer: A network visualization tool for human brain connectomics. PloS One, 8: 1-15. DOI: 10.1371/journal.pone.0068910

Xiao, H., Y. Yang, J.H. Xi and Z.Q. Chen, 2015. Structural and functional connectivity in traumatic brain injury. Neural Regenerat. Res., 10: 2062-2071. DOI: $10.4103 / 1673-5374.172328$

Xu, T., K.R. Cullen, B. Mueller, M.W. Schreiner and K.O. Lim et al., 2016. Network analysis of functional brain connectivity in borderline personality disorder using resting-state fMRI. NeuroImage: Clin., 11: 302-315. DOI: $10.1016 /$ j.nicl.2016.02.006

Zhang, W.T., Z. Jin, G.H. Cui, K.L. Zhang and L. Zhang et al., 2003. Relations between brain network activation and analgesic effect induced by low vs. high frequency electrical acupoint stimulation in different subjects: A functional magnetic resonance imaging study. Brain Res., 982: 168-178. DOI: 10.1016/S0006-8993(03)02983-4

Zhang, Y., H. Zhang, X. Chen, S.W. Lee and D. Shen, 2017. Hybrid high-order functional connectivity networks using resting-state functional MRI for mild cognitive impairment diagnosis. Sci. Rep., 7: 1-15. DOI: $10.1038 / \mathrm{s} 41598-017-06509-0$

Zhou, Y., M. Liang, T. Jiang, L. Tian and Y. Liu et al., 2007. Functional dysconnectivity of the dorsolateral prefrontal cortex in first-episode schizophrenia using resting-state fMRI. Neurosci. Lett., 417: 297-302. DOI: 10.1016/j.neulet.2007.02.081 


$\begin{array}{llll}\text { Abbreviations } & \text { EEG } & \text { Electroencephalography } \\ \text { MRI } & \text { Magnetic Resonance Imaging } & \text { FC } & \text { Functional Connectivity } \\ \text { PET } & \text { Positron Emission Tomography } & \text { DMN } & \text { Default mode network } \\ \text { FMRI } & \text { Functional Magnetic Resonance } & \text { Glasgow Coma Scale } \\ & \text { Imaging (fMRI) } & \text { DWI } & \text { Susceptibility Weighted Imaging } \\ \text { DSI } & \text { Diffusion Spectrum Imaging } & \text { FlAIR } & \text { Diffusion Weighted Imaging } \\ \text { DMRI } & \text { Diffusion Magnetic Resonance } & \text { NMR } & \text { Fluid Attenuated Inversion Recovery } \\ & \text { Imaging } & \text { GMD } & \text { Nuclear Magnetic Resonance } \\ \text { WM } & \text { White Matter } & \text { ADC } & \text { Gray Matter Density } \\ \text { DTI } & \text { Diffusion Tensor Imaging } & \text { NAWM } & \text { Apparent Diffusion Coefficient } \\ \text { FA } & \text { Functional Anisotropy } & \text { WMD } & \text { White Matter Density } \\ \text { DKI } & \text { Diffusion Kurtosis Imaging } & \text { NAGM } & \text { Normal-Appearing Gray Matter } \\ \text { MD } & \text { Mean diffusivity } & \text { NABT } & \text { Normal-Appearing Brain Tissue } \\ \text { FODF } & \text { Fiber Diffusion Orientation } & \text { SDP } & \text { Slow Diffusion Phase } \\ \text { TBI } & \text { Distribution Function } & \text { FDP } & \text { Fast Diffusion Phase } \\ \text { CSD } & \text { Traumatic Brain Injury } & \text { SC } & \text { Structural Connectivity } \\ \text { BOLD } & \text { Constrained Spherical Deconvolution } & \text { MEG } & \text { Magnetoencephalography }\end{array}$

